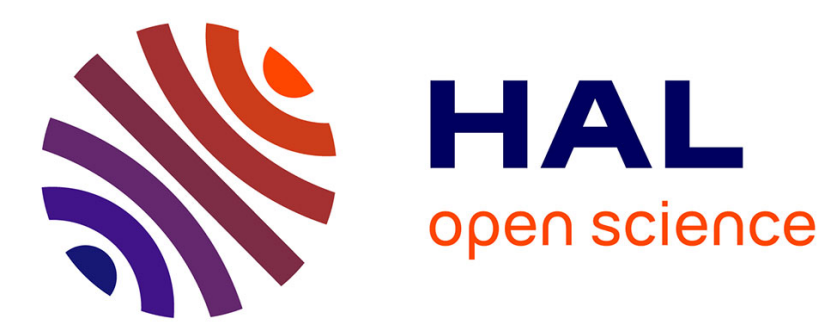

\title{
Aerodynamic analysis of a C-class-like catamaran in simplified unsteady wind conditions using LES and URANS modeling
}

Alessandro Fiumara, Nicolas Gourdain, Vincent Chapin, Julien Senter

\section{To cite this version:}

Alessandro Fiumara, Nicolas Gourdain, Vincent Chapin, Julien Senter. Aerodynamic analysis of a C-class-like catamaran in simplified unsteady wind conditions using LES and URANS modeling. Journal of Wind Engineering and Industrial Aerodynamics, 2018, 180, pp.262-275. 10.1016/j.jweia.2018.08.008 . hal-01874317

\section{HAL Id: hal-01874317 https://hal.science/hal-01874317}

Submitted on 14 Sep 2018

HAL is a multi-disciplinary open access archive for the deposit and dissemination of scientific research documents, whether they are published or not. The documents may come from teaching and research institutions in France or abroad, or from public or private research centers.
L'archive ouverte pluridisciplinaire HAL, est destinée au dépôt et à la diffusion de documents scientifiques de niveau recherche, publiés ou non, émanant des établissements d'enseignement et de recherche français ou étrangers, des laboratoires publics ou privés. 


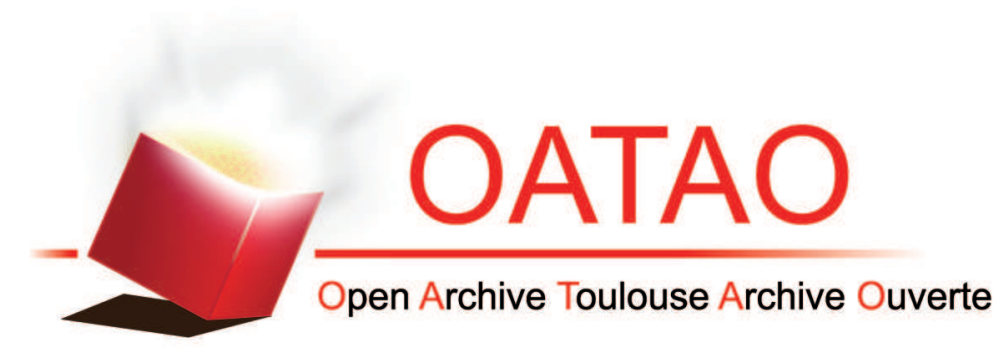

\section{Open Archive Toulouse Archive Ouverte (OATAO)}

OATAO is an open access repository that collects the work of some Toulouse researchers and makes it freely available over the web where possible.

This is an author's version published in: https://oatao.univ-toulouse.fr/20807

Official URL :https://doi.org/10.1016/j.jweia.2018.08.008

\section{To cite this version :}

Fiumara, Alessandro and Gourdain, Nicolas and Chapin, Vincent and Senter, Julien Aerodynamic analysis of a Cclass-like catamaran in simplified unsteady wind conditions using LES and URANS modeling. (2018) Journal of Wind Engineering and Industrial Aerodynamics, 180. 262-275. ISSN 0167-6105

Any correspondence concerning this service should be sent to the repository administrator: tech-oatao@listes-diff.inp-toulouse.fr 


\title{
Aerodynamic analysis of a C-class-like catamaran in simplified unsteady wind conditions using LES and URANS modeling
}

\author{
Alessandro Fiumara $^{\mathrm{a}, *}$, Nicolas Gourdain ${ }^{\mathrm{b}}$, Vincent Chapin ${ }^{\mathrm{b}}$, Julien Senter ${ }^{\mathrm{c}}$ \\ a Assystem Technologies and ISAE-Supaéro, Toulouse, France \\ ${ }^{\mathrm{b}}$ ISAE-Supaéro, Toulouse, France \\ ${ }^{c}$ Assystem Technologies, Toulouse, France
}

\section{Introduction}

The interest for wingsails has grown since their introduction on America's Cup catamarans in 2013. Wingsails enhance the yacht performance thanks to the achievement of larger lift-to-drag ratio and maximum lift coefficients with respect to soft sails. However, the larger aerodynamic forces acting on the wingsail can compromise the stability of the yacht during navigation especially in unsteady conditions, e.g. during maneuvers or under the effect of gusts. Since this instability can easily bring the yacht to capsize, a research of the effect of the flow unsteadiness is necessary to prevent the occurring of such an event.

Though similar to aeronautical wings (two-element slotted wing), wingsails have some specific features (e.g. the use of symmetric airfoils, the low Reynolds number as well as its use in highly unsteady flow conditions) that complicate flow analysis with respect to the aeronautical domain. The aerodynamic studies on wingsails are indeed not numerous with some experimental campaigns performed to characterize the wingsail performance without focusing on the flow physics around the rig (Magherini et al., 2014), (Blakeley et al., 2012) and (Blakeley et al., 2015)). (Fiumara et al., 2016a) carried out wind tunnel tests analyzing the flow physics, particularly in the wingsail slot zone, deepening the study of (Chapin et al., 2015). (Fiumara et al., 2016b) also described the strong influence of the slot size on the stall behavior of a scale wingsail performing URANS simulations. All these studies were however performed in steady flow conditions without taking into account the sea boundary layer and wind unsteadiness. The flow variations can lead to significant modifications of the operating point of the slot and hence of the aerodynamic forces acting on the wingsail. One of the causes of the increase of the aerodynamic forces is the onset of leading-edge vortices (Anderson, 2005), (Breitsamter, 2008). These flow structures typically take place over thin airfoil shapes in unsteady flow conditions, like flapped wings, and are largely exploited by insects and flying animals to enhance their flying capabilities (Maxworthy, 1979; Ellington et al., 1996; Muijres et al., 2008). On bat wings, the increase in lift due to the LEV is of $40 \%$ (Muijres et al., 2008). LEVs are also exploited in the aeronautic field to increase the lift of delta wings. In the naval domain, (Viola and Arredondo-Galeana, 2017), performing PIV experimental tests, observed and analyzed the formation of LEV on a soft spinnaker estimating the LEV contribution to the sail global lift at more than $10 \%$.

The aim of this study is then to detail the influence of the wind unsteadiness on the flow physics and on the wingsail performances of a Cclass catamaran-like geometry. Two complementary numerical approaches have been exploited, LES and URANS with two different solvers. The LES is indeed more adapted to compute separated flow in highly turbulent environments. However, due to the huge computational requirements, LES is used, even in the aeronautical domain, in the analysis of multi-element wings only on extruded airfoil geometries (Deck, 2005), (Deck and Laraufie, 2013) rather than on full three-dimensional wings. In the naval domain, except the DES approach used by (Viola et al., 2014) to analyze high separated regions on soft sails, LES has never been exploited for the analysis of a full three-dimensional wingsail. The comparison between the LES and URANS solutions on a given wingsail geometry can give an indication of the actual capabilities of the URANS to predict the flow influence on a wingsail in unsteady wind conditions.

\section{Numerical methodology}

\subsection{Geometry}

A C-class hull catamaran was designed based on the overall length

\footnotetext{
* Corresponding author.

E-mail addresses: afiumara@assystem.com, afiumara@assystemtechnologies.com (A. Fiumara), nicolas.gourdain@isae.fr (N. Gourdain), vincent.chapin@isae.fr (V. Chapin), jsenter@assystemtechnologies.com (J. Senter).
} 


\begin{tabular}{|c|c|c|c|}
\hline \multicolumn{2}{|c|}{ Nomenclature } & $\mathrm{k}$ & Turbulent kinetic energy $\left(\mathrm{m}^{2} / \mathrm{s}^{2}\right)$ \\
\hline$\alpha$ & Winocail local anole of attack $r^{\circ}$ & LFV & Jeadino Fdoe Vortey \\
\hline$\delta$ & Flap deflection angle $\left(^{\circ}\right)$ & $\mathrm{m}$ & Exponent of the power law for velocity profile \\
\hline AW & Apparent Wind & o & Overlap of the flap with the main \\
\hline AWA & Apparent Wind Angle $\left({ }^{\circ}\right)$ & $\operatorname{Re}$ & Reynolds number \\
\hline AWS & Apparent Wind Speed $(\mathrm{m} / \mathrm{s})$ & $\operatorname{Re}_{\mathrm{c} 2}$ & Reynolds number referred to the flap chord \\
\hline BS & Boat speed $(\mathrm{m} / \mathrm{s})$ & $\mathrm{S}$ & Wingsail surface $\left(\mathrm{m}^{2}\right)$ \\
\hline $\mathrm{C} \mu$ & Momentum coefficient & SC & Stall cell \\
\hline c & Total chord of the wingsail (m) & $\mathrm{t}$ & Time (s) \\
\hline$c_{1}$ & Main chord (m) & T.E. & Trailing Edge \\
\hline$c_{2}$ & Flap chord (m) & $\mathrm{Tu}$ & Turbulence intensity \\
\hline$C_{D}$ & Drag coefficient & TW & True Wind \\
\hline $\mathrm{C}_{\mathrm{F}}$ & Skin friction coefficient & TWA & True Wind Angle $\left({ }^{\circ}\right.$ ) \\
\hline $\mathrm{C}_{\mathrm{L}}$ & Lift coefficient & TWS & True Wind Speed $(\mathrm{m} / \mathrm{s})$ \\
\hline $\mathrm{Cp}$ & Pressure coefficient & $\mathrm{u}, \mathrm{v}, \mathrm{w}$ & Velocity components on the steady wind axis $(\mathrm{m} / \mathrm{s})$ \\
\hline $\mathrm{F}^{+}$ & Non-dimensional wind frequency $\left(\mathrm{f}_{\mathrm{g}} \mathrm{c}_{2} / \mathrm{V}_{\infty}\right)$ & $\mathrm{V}$ & Velocity magnitude $(\mathrm{m} / \mathrm{s})$ \\
\hline$f_{g}$ & Wind frequency $(\mathrm{Hz})$ & $\mathrm{V}_{\infty}$ & Freestream velocity magnitude $(\mathrm{m} / \mathrm{s})$ \\
\hline $\mathrm{g}$ & Gap dimension of the slot (mm) & WG-URA & INS URANS simulation without wind unsteadiness \\
\hline G-LES & LES simulation in unsteady wind & $\mathrm{x}, \mathrm{y}, \mathrm{z}$ & Axes of the wingsail reference system \\
\hline G-URAN & $S$ URANS simulation in steady wind & $\mathrm{x}_{\mathrm{s}}, \mathrm{y}_{\mathrm{s}}, \mathrm{z}_{\mathrm{s}}$ & Axes of the sea reference system \\
\hline $\mathrm{H}$ & Wingsail height (m) & & $\mathrm{x}$-coordinate of the flap rotation axis \\
\hline $\mathrm{H}_{\mathrm{c}}$ & Catamaran hull height $(\mathrm{m})$ & $\mathrm{x}_{\mathrm{w}}, \mathrm{y}_{\mathrm{w}}, \mathrm{z}_{\mathrm{v}}$ & w Steady wind axes \\
\hline $\mathrm{H}_{\mathrm{h}}$ & Hull elevation from the sea surface (m) & $\mathrm{y}_{\mathrm{F}}$ & Transversal distance between the flap L.E. and the main T.E \\
\hline$h_{\text {ref }}$ & Reference height of the atmospheric boundary layer (m) & $\mathrm{z}^{*}$ & Normalized height position $\mathrm{z} / \mathrm{H}$ \\
\hline
\end{tabular}

and beam dimensions imposed by the class rule (Fig. 1). The trampoline was also modeled with a solid platform. The rig is the two-element wingsail analyzed by (Chapin et al., 2015) and scaled in a way to achieve a surface close to the maximal one imposed by the class rules $\left(27.87 \mathrm{~m}^{2}\right)$.

The gap distance between the trampoline and the wingsail is of $0.03 \mathrm{H}$. Usually, sailors introduce a twist to adjust the heeling moment of the wing to the wind conditions. However, since the wingsail twist is variable according to sailing conditions and considering the difficulty to find a twist distribution along the wingspan compatible with real utilization, it was decided to use an untwisted wingsail to reduce the number of parameters in the geometry. The flap is also not twisted and deflected by an angle $(\delta)$ of $35^{\circ}$ after a rotation about the hinge line located at $90 \%$ of the main root chord and parallel to the main T.E. The gap $(g)$ between the two elements is of $0.6 \% c_{1 r o o t}$ when the flap is not deflected. The geometrical values of the gap and the hinge line position were drawn on the wingsail schemes in the America's Cup AC 50 class rules (America's

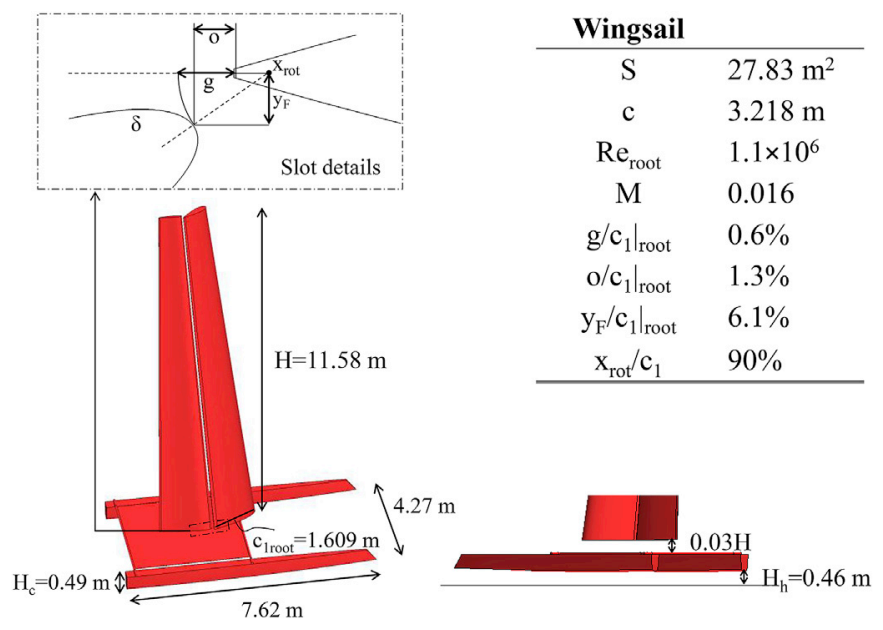

Fig. 1. Geometry of the catamaran with its main parameters.
Cup Class Rule, 2015). These wingsails have similar design and features to the ones used on the C-class catamarans. The flap deflection of $35^{\circ}$ is a setting used by sailors during navigation along the downwind leg.

\subsection{Computation domain}

A box domain with a squared section was used for the numerical analyses. The side length is of $47 c_{\text {root }}$ while the height is of $2 H$ (Fig. 2).

The catamaran was located in the middle of the box domain with the hull rotated with respect to the inlet wall normal of $-41.4^{\circ}$. Port side is then oriented toward the inlet wall. The wingsail is instead rotated by $-8^{\circ}$ with respect to the inlet wall normal. Furthermore, the hull of the catamaran is not in contact with the box bottom surface, but a distance of $H_{h}=0.94 H_{c}$ was imposed to simulate the catamaran elevation from the sea surface introduced by the hydrofoils.

The wingsail and wind reference frames are represented in Fig. 3 together with the scheme of the catamaran. The wingsail reference frame $(x, y, z)$ has the origin located on the L.E. of the wing root section with the $\mathrm{x}$-axis directed towards the T.E. and the z-axis directed upwards. The wind reference frame $\left(x_{w}, y_{w}, z_{w}\right)$ has the origin translated of $-2.65 H_{c}$ in the z-direction $\left(z_{w}=z-2.65 H_{c}\right)$. The $x_{w}$ and $y_{w}$ axes are respectively orthogonal and parallel to the apparent inlet wall of the box domain (i.e.

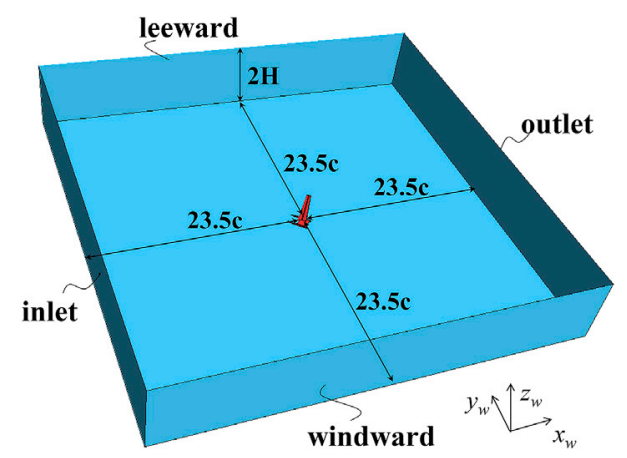

Fig. 2. C-class catamaran inside the computation domain. 


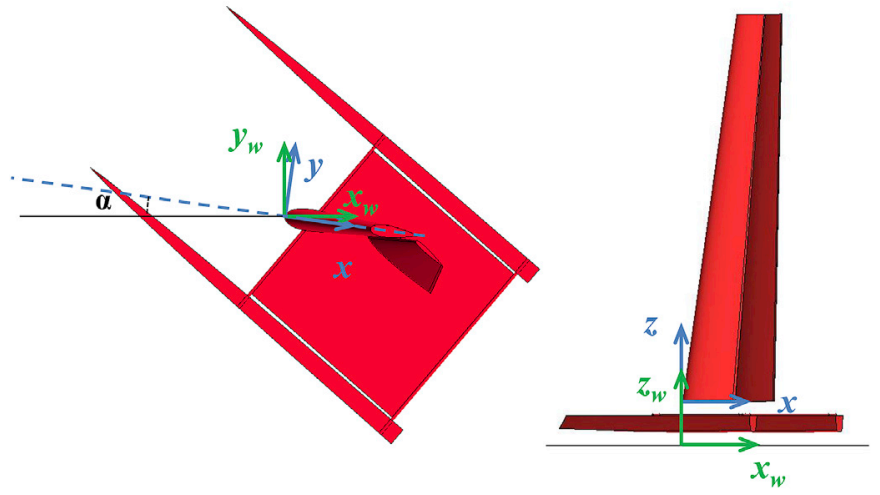

Fig. 3. Representation of the reference frames on the catamaran geometry.

the wind system is rotated by $8^{\circ}$ around the $\mathrm{z}$-axis with respect to the wing system).

\subsection{Wind conditions}

The wind conditions imposed on the simulations take into account the effect of the atmospheric boundary layer in a simplified manner. Wind conditions are modeled with a generic power law of the TWS (Marchaj, 1980) (Flay and Jackson, 1992) as follow:

$\operatorname{TWS}\left(z_{w}\right)=T W S_{h_{r e f}} \cdot\left(\frac{z_{w}}{h_{\text {ref }}}\right)^{m}$ with $h_{\text {ref }}=15 \mathrm{~m}$

The exponent value $(m)$ was imposed at $1 / 6$ which is typical, after (Marchaj, 2003), of an atmospheric turbulent boundary layer above the sea water in average sea conditions. This value is whatever considered elevated after the measurements made by (Holmes, 2017), (Cook, 1986) and (Charnock, 1955) who propose, instead, an exponent of the order of $1 / 10$. The influence of this exponent will be discussed.

Starting from the TWS distribution along $\mathrm{z}_{\mathrm{W}}$-axis, the apparent wind was estimated from the velocity triangle with the boat speed (BS) of a Cclass catamaran in downwind conditions and the true wind speed (TWS). The $B S$ was imposed at $6.17 \mathrm{~m} / \mathrm{s}$ (Magherini et al., 2014) while the TWS at the reference height was considered to be $4.11 \mathrm{~m} / \mathrm{s}$ (Magherini et al., 2014). Thus, at the reference height, the apparent wind speed (AWS) is $5.16 \mathrm{~m} / \mathrm{s}$ with an apparent wind angle (AWA) of $41.4^{\circ}$ (Table 1 ).

This apparent wind angle corresponds to the angle of the hull of the catamaran with respect to the box domain. Hence the wind component at $z_{w}=h_{r e f}$ is normal to the inlet wall of the box. The correspondent velocity triangle is reported in Fig. 4. The AWS and AWA were calculated locally at different heights to take into account the TWS variation along the $z_{w^{-}}$ axis. In Table 2 the AWS, the AWA and the local angle of attack of the wing are reported at different heights, (respectively the water plan, the trampoline surface, the sections of the wingsail located at $z^{*}=0,0.25$, $0.50,0.75$ and 1 ). The hull of the catamaran and hence the $B S$ (leeway angle is $0^{\circ}$ ) is oriented with an angle of $41.4^{\circ}$ with respect to the inlet wall while the wingsail has an angle of $8^{\circ}$ with respect to this same surface (Fig. 4). Since the wingsail is untwisted, the difference between $A W A$ and the wingsail angle of attack $\alpha$ is constant along $z_{w}$ and equal to $33.4^{\circ}$.

At $z_{w}=0$, the apparent wind has same magnitude and direction than $B S$ since, here, the TWS is null. Moving upwards the AWA tends to

\section{Table 1}

Velocity triangle of the catamaran at the reference height in the atmospheric boundary layer in downwind conditions.

\begin{tabular}{lllll}
\hline TWS & TWA & BS & AWS & AWA \\
\hline $8 \mathrm{kts}$ & $124^{\circ}$ & $12 \mathrm{kts}$ & $10 \mathrm{kts}$ & $41.4^{\circ}$ \\
$4.11 \mathrm{~m} / \mathrm{s}$ & & $6.17 \mathrm{~m} / \mathrm{s}$ & $5.16 \mathrm{~m} / \mathrm{s}$ & \\
\hline
\end{tabular}

Table 2

Apparent wind characteristics at different heights.

\begin{tabular}{llllll}
\hline $\mathrm{z}_{\mathrm{W}}(\mathrm{m})$ & $\mathrm{z}^{*}=\mathrm{z} / \mathrm{H}$ & TWS $(\mathrm{m} / \mathrm{s})$ & AWS $(\mathrm{m} / \mathrm{s})$ & AWA $\left(^{\circ}\right)$ & $\alpha\left(^{\circ}\right)$ \\
\hline 0.000 & -0.112 & 0 & 6.17 & 0 & -33.4 \\
1.000 & -0.026 & 2.62 & 5.19 & 24.8 & -8.6 \\
1.300 & 0.00 & 2.74 & 5.17 & 26.1 & -7.3 \\
4.195 & 0.250 & 3.33 & 5.12 & 32.6 & -0.8 \\
7.090 & 0.500 & 3.63 & 5.12 & 36.0 & 2.6 \\
9.985 & 0.750 & 3.85 & 5.13 & 38.4 & 5.0 \\
12.880 & 1.000 & 4.01 & 5.15 & 40.3 & 6.9 \\
15.000 & 1.183 & 4.11 & 5.16 & 41.4 & 8.0 \\
\hline
\end{tabular}

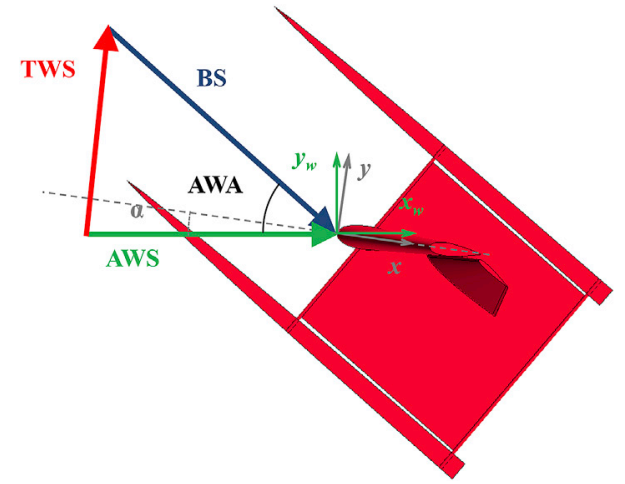

Fig. 4. Velocity triangle in the atmospheric boundary layer at $z_{w}=h_{\text {ref }}$.

increase up to the value of $41.4^{\circ}$ at $z_{w}=h_{\text {ref. Along the wingsail }}$ $\left(0<z^{*}<1\right)$, the $A W A$ varies by $14.2^{\circ}$ from the root to the tip of the wing. Here, instead, the $A W S$ is almost constant ranging from $5.12 \mathrm{~m} / \mathrm{s}$ to $5.17 \mathrm{~m} / \mathrm{s}$. Subsequently, the angle of attack of the low wing sections is lower than the one felt by higher sections and goes negative. The apparent wind distribution was projected on the wind reference frame and applied at the inlet, windward and leeward wall of the box domain in the URANS simulation in steady wind conditions (WG-URANS).

The use of the exponent of $1 / 10$ in the velocity profile power law (instead of the 1/6 used in this paper) would affect the AWS and AWA distributions, especially on the low wing sections while, on the high sections, the velocity variations are small (less than $1 \%$ on the wing tip). The AWS would increase from $0.48 \mathrm{~m} / \mathrm{s}$ on the wing root to $0.04 \mathrm{~m} / \mathrm{s}$ on the wing tip. The growth in $A W A$ is $5.4^{\circ}$ on the wing root and $0.45^{\circ}$ on the wing tip respectively leading to an increase in $\alpha$. Thus, because of the larger angle of attack, the flow would be more prone to separate especially on the low wing sections while on the high wing sections the flow characteristics would remain unchanged.

\subsection{Simplified unsteady wind model}

As a first step towards an unsteady wind model, the considered unsteadiness was modeled using a sinusoidal variation to the $x_{w}$ component of the apparent wind $(u)$ at different heights following the pulsing wind concept described by (Bethwaite, 1996). The sinusoidal law (Equation (1)) was set in a way to obtain $u\left(z_{w}\right)$ variation around its value imposed in steady wind condition, and the amplitude estimated from the wind turbulence level and a dimensionless frequency carefully chosen.

$u(z, t)=u(z, t=0) \cdot\left[A_{0} \sin \left(\frac{2 F^{+} c_{2}}{V_{\infty}} \pi t\right)+1\right]$

A turbulence level $(\mathrm{Tu})$ of $13.5 \%$ was chosen following the experimental analyses performed by (Beaupuits et al., 2004), (Türk and Emeis, 2010) and (Hui et al., 2009a) on the wind speed characterization in an open environment. The turbulence level is imposed constant on the height. The estimation of $\mathrm{A}_{0}$ was carried out from the definition of turbulence intensity $\left(T u=u^{\prime} / V_{\infty}\right.$, where $u^{\prime}$ is the RMS of the turbulent 
velocity fluctuations) and considering the turbulent velocity fluctuation as the periodical component of the wind unsteadiness $V_{\infty} A_{0} \sin \left(\frac{2 F^{+} c_{2}}{V_{\infty}} \pi t\right)$. The RMS of the fluctuating component is $u^{\prime}=\frac{V_{\infty} A_{0} \sqrt{2}}{2}$ then $T u=\frac{A_{0} \sqrt{2}}{2}=0.135$. Hence, the amplitude of the flow unsteadiness was estimated to be $A_{0}=0.19$. The true wind, which is aligned with the $\mathrm{x}_{\mathrm{W}}$ axis, fluctuates in the $\mathrm{x}_{\mathrm{W}}$ direction leading to an oscillation of the TWS magnitude but without modifying its direction (TWA).

The dimensionless frequency of the velocity variation $\left(F^{+}=f_{g} c_{2} / V_{\infty}\right)$ was set at $0.623\left(f_{g}=2 \mathrm{~Hz}\right)$. Usually, the wind frequency is made by a spectrum of frequencies ranging from $10^{-2} \mathrm{~Hz}$ up to $10 \mathrm{~Hz}$ on the coast (Hui et al., 2009b), (Shiau and Chen, 2002). The sinusoid wavelength is $2.5 \mathrm{~m}$, which is the same order of magnitude of the turbulent eddies inside the sea boundary layer which range from $2 \mathrm{~m}$ to $10 \mathrm{~m}$ (Peña et al., 2010). In the present study, a single frequency was chosen to model simple wind unsteadiness. The choice of a lower frequency would have been more adapted to model a typical pulsing wind but the choice of this value has been dictated by the need to reduce the simulated time and hence the computational cost of the simulations, especially the LES one. Nevertheless, even if wind frequencies $\left(f_{g}\right)$ higher than $2 \mathrm{~Hz}$ can rarely be observed in nature, the same value of the corresponding dimensionless frequency $F^{+}=0.623$ can be reached for lower gust frequencies on larger boats. The $F^{+}$depends indeed on the flap chord length of the wingsail. Thus, the study of unsteady wind conditions at higher $F^{+}$appears interesting.

The application of the sinusoidal law to the $x_{w}$-component of the apparent wind distribution leads to a time variation of both the AWS and the $A W A$ which is coherent along $z_{w}$-axis following the pulsing wind concept proposed by Bethwaite (1996). Hence, wind conditions will be representative of wind unsteadiness associated with a vortex with a vertical axis. The distribution of the AWS (magnitude) and the angle of attack felt by the wingsail at different times are represented in Fig. 5.

The AWS, at a fixed time, is almost constant in $\mathrm{z}_{\mathrm{W}}$ locations corresponding to the wingsail position (i.e. $1.30 \mathrm{~m}<z_{w}<12.88 \mathrm{~m}$ ) and varies between $4.27 \mathrm{~m} / \mathrm{s}$ and $6.12 \mathrm{~m} / \mathrm{s}$ over time. The angle of attack variation mainly involves the low wingsail sections and it decreases tipwards. Since the wingsail lies completely inside the sea boundary layer $\left(\mathrm{z}_{\mathrm{wtip}}=12.88 \mathrm{~m}<15 \mathrm{~m}=\mathrm{h}_{\text {ref }}\right.$ ), the angle of attack of the wing does not oscillate around $8^{\circ}$. The oscillation of the angle of attack around $8^{\circ}$ would have been possible only above the $\mathrm{h}_{\mathrm{ref}}\left(\mathrm{z}_{\mathrm{w}}=15 \mathrm{~m}\right)$. At the wingsail root, $\alpha$ ranges between $-10.3^{\circ}$ and $-5^{\circ}$. At the mid-span $\left(z^{*}=0.50\right)$ the angle of attack ranges between $1.5^{\circ}$ and $3.5^{\circ}$; at the wing tip, the variation is between $6.6^{\circ}$ and $7^{\circ}$

The apparent wind was projected on the wind reference frame and $u\left(t, z_{w}\right)$ and $v\left(z_{w}\right)$ components were applied as inlet conditions for the URANS and LES simulations taking into account the unsteady wind model (G-URANS and G-LES).

\subsection{Unsteady rans modeling}

An unstructured mesh made by polyhedra and prism layers was generated inside the computational domain. The mesh size is particularly fine close to the wing surface and in the wake. The finest refinement was applied in the slot region (Fig. 6). The prism layers were set on the wingsail surface to model the boundary layer. The size of the first layer was imposed in a way to have $y^{+}<1$ on the entire surface. The final mesh counts 32 million cells.

Simulations were run using STAR-CCM + v10.02 with and without the unsteady wind modeling respectively noted as G-URANS and WGURANS. Velocity inlet conditions were imposed on the inlet, windward, leeward walls of the domain. The velocity values were imposed by a table specifying the three velocity components in the wind reference frame. These values were then interpolated by the solver and exploited as velocity conditions. A pressure outlet condition was specified on the outlet surface while the sea surface was modeled with a slip wall condition. In this way, the TWS profile imposed as inlet boundary condition does not evolve in space. The TWS remains at zero on the sea surface while the AWS has the boat velocity value. The k- $\omega$ SST of (Menter, 1994) was used for modeling turbulence. An incompressible solver was applied for the computations. An upwind second order scheme was used for the spatial resolution and the time solution was performed by first-order Runge-Kutta scheme.

A first steady simulation was run for 6000 iterations to achieve first convergence. Simulations were then carried on switching to the unsteady option in both the WG-URANS and the G-URANS cases. The time step was set at $2 \times 10^{-3}$ s. The simulated time of the WG-URANS case was of $2 \mathrm{~s}$ while the G-URANS case was extended to $8 \mathrm{~s}$ for simulating 16 wind periods for achieving a complete convergence in the wind response of the wingsail. The aerodynamic parameters were averaged over the last 6 wind periods.

The simulations were run using 64 cores on bi-XeonE5-2670 Octo processors, $2.60 \mathrm{GHz}, 64 \mathrm{~GB}$ RAM. The steady analysis needed a computation time of 2 days. The WG-URANS then converged in 4 days while the G-URANS needed 16 days (CPU time $0.24 \times 10^{5} \mathrm{~h}$ ).
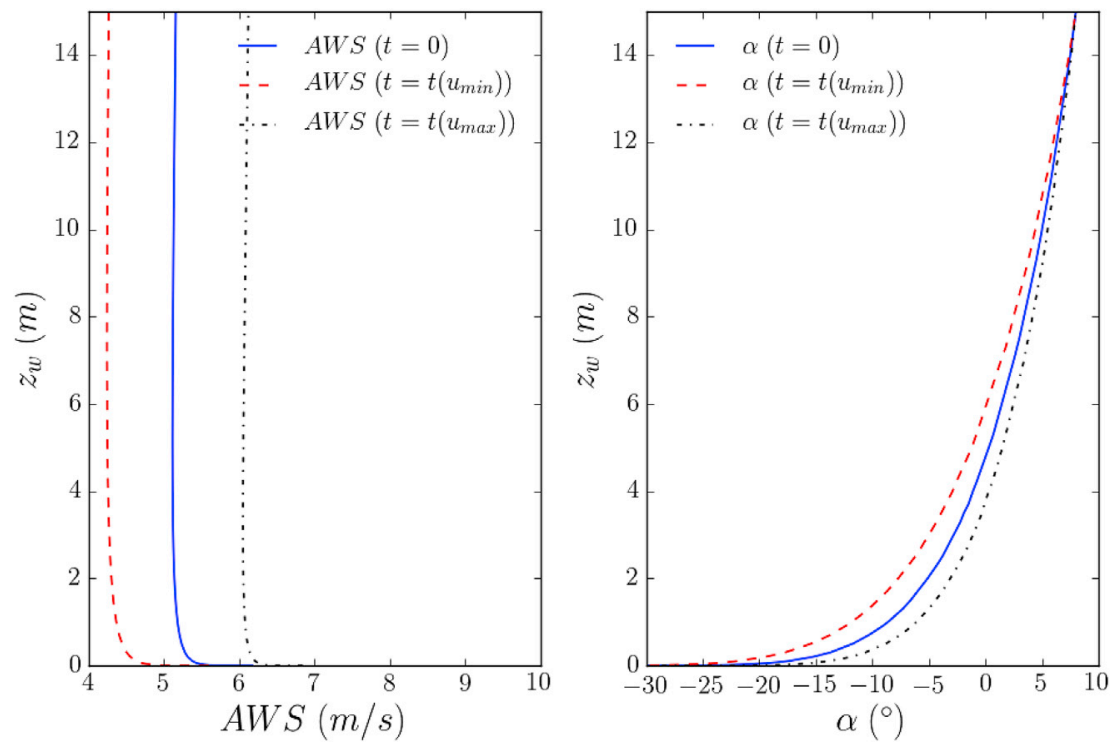

Fig. 5. Apparent wind speed (AWS) and angle of attack profiles at different times, showing the effect of the unsteady wind modeling. 

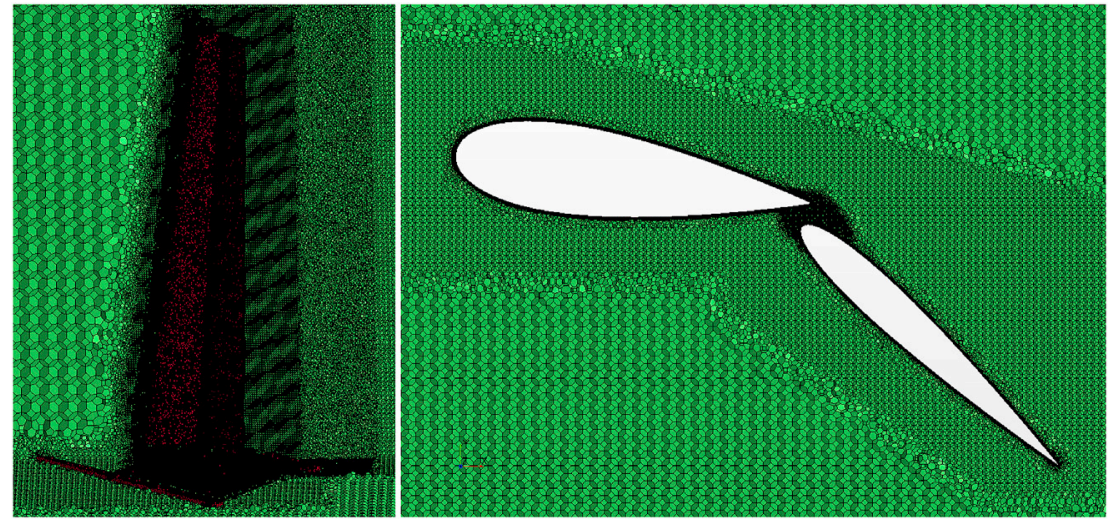

Fig. 6. Views of the polyhedral mesh used for the unsteady RANS simulations.

Further simulations were then performed modifying the wind frequency from the nominal $F^{+}=0.623$ to $F^{+}=0.156,0.312,1.246$ and 2.492 .

\subsection{Les modeling}

The LES simulation, here named G-LES, was performed with CharLES $X$ (Bermejo-Moreno et al., 2013), an unstructured solver, originally developed by Stanford, solving the compressible Navier-Stokes equations. A fourth order central scheme in space and a second order in time were used for the computation. The catamaran geometry and the box domain were scaled with a ratio of 0.1 in a way to reduce the cell numbers of the grid keeping the same accuracy for the large turbulent structures. Coincidentally the velocity condition imposed was increased of a scale factor of 10 to keep the original Reynolds number. Furthermore, the Mach number is lower than 0.3 on the entire domain so that the G-LES flow conditions are comparable with the ones of the G-URANS. As in the case of the G-URANS analysis, the velocity condition at the inlet was applied to specify the different velocity components in the $z_{w}$-direction. These components have then been interpolated by the code on the inlet surface.

The hexahedral mesh used for the LES computation was generated with ICEM CFD (Fig. 7).

A first coarse mesh counting 60 million cells was created to obtain a solution that was then carried on the fine mesh. The final grid counts 120 Million cells with a $z^{+}=400$, an $x^{+}=200$ and a $y^{+}$ranging between 15 and 20. The Vreman subgrid-scale model (Vreman, 2004) was adopted to estimate the unresolved structures taking into account wall effects on turbulence. A wall law approach is used, on the wingsail surfaces, to increase the accuracy of the simulation in the wall region (WMLES) (Kawai and Larsson, 2012). The use of a wall model is still mandatory to reduce the number of cells needed to correctly resolve the turbulent flow patterns (with a wall-resolved approach, the number of points scale as $\mathrm{Re}^{1.8}$ and the time step is reduced by a factor 10 compared to wall-model approach). The wall model implemented in the solver has been used and validated in previous studies on high-lift devices (Bodart and Larsson, 2011), (Bodart et al., 2013) as well as on thick airfoils geometries close to the one described in this paper (Gourdain et al., 2016). A transitional model is also implemented in the solver (Bodart and Larsson, 2012).

The time step used is $2 \times 10^{-6} \mathrm{~s}$. A first computation was run on a coarser mesh, in steady wind conditions, for $5 \times 10^{5}$ time steps, i.e. $0.1 \mathrm{~s}$. The simulation was then carried on the coarse mesh activating the wind unsteady model for further $10^{6}$ time steps, i.e. $0.2 \mathrm{~s}$. The final simulation was then run on the final refined mesh for a total simulated time of $0.05 \mathrm{~s}$, i.e. 10 wind periods. The aerodynamic flow was averaged over the last 5 wind periods. The simulation was run on 400 cores on the HPC EOS of CALMIP made by Intel(r) IVYBRIDGE $2.80 \mathrm{GHz}, 64 \mathrm{~GB}$ RAM. The total CPU time for the LES simulation was $5 \times 10^{5} \mathrm{~h}$.

\section{Urans and les comparison}

\subsection{Flow topology over the wingsail}

The iso-surfaces on the Q-criterion have been carried out on the G-LES and G-URANS simulations in order to compare the flow topology obtained by the two numerical approaches (Fig. 8). The G-LES allows simulating the small turbulent structures that are not taken into account by the G-URANS analysis. However, the two methodologies give quite the same flow characteristic around the wing.

Four structures emitted from the flap surface can be observed in the two cases $\left(C_{1}, C_{2}, C_{3}\right.$, and $\left.C_{4}\right)$. These mushroom shape structures are known as stall cells. Stall cells usually appear on wings at high angles of attack in the post-stall condition before the deep stall regime (Yon and Katz, 1997). The origin of these cells is still not completely understood,
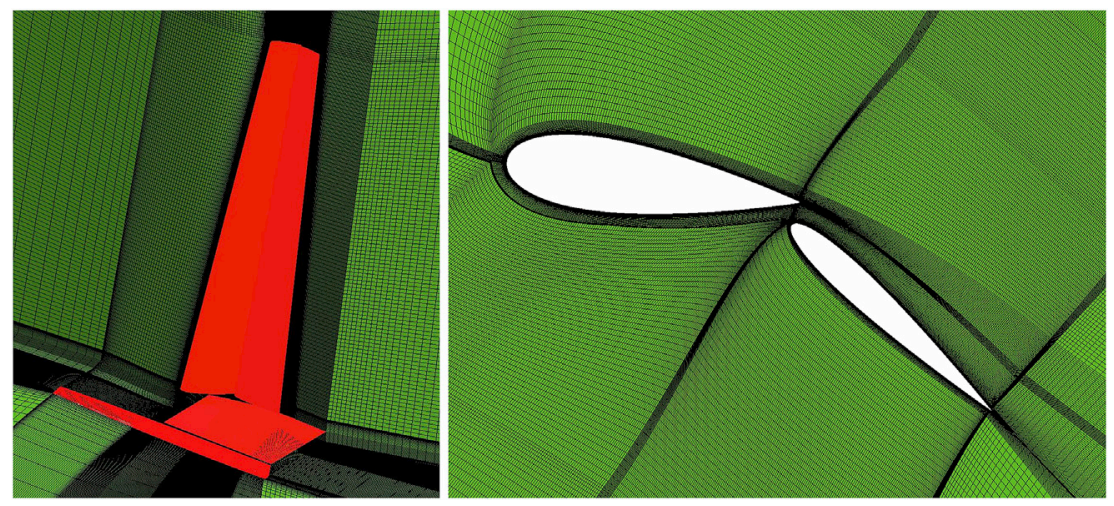

Fig. 7. Views of the hexahedral mesh used for the LES computation. 

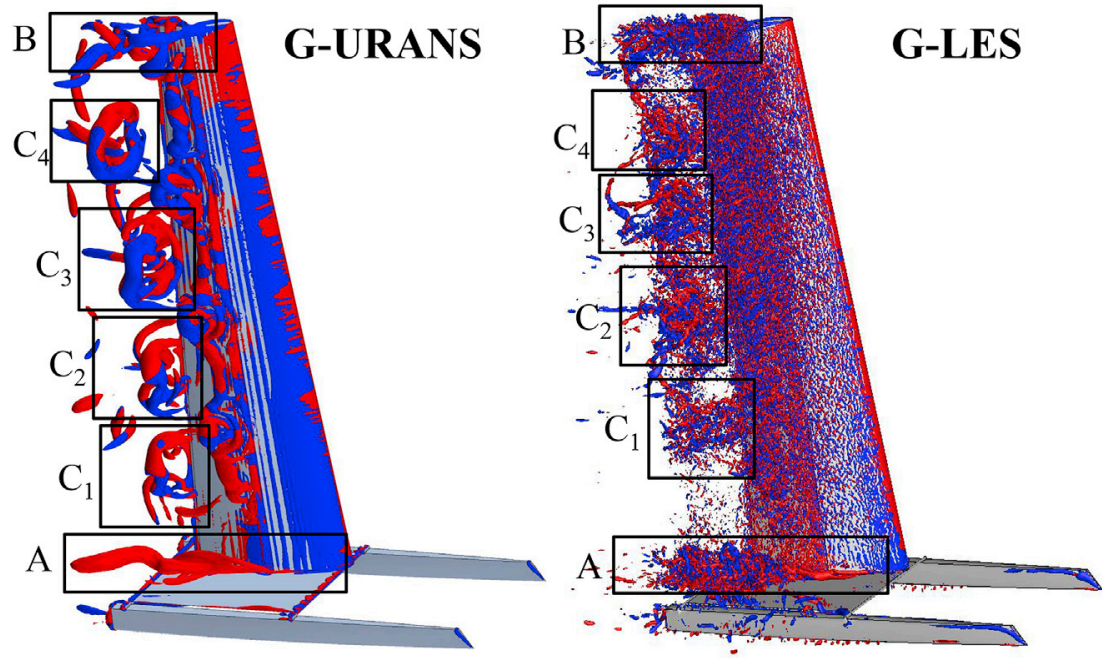

Fig. 8. Q-criterion isosurfaces with the helicity color map: G-URANS simulation $\left(Q=100 / \mathrm{s}^{2}\right)$ and G-LES simulation $\left(Q=10^{7} / s^{2}\right), R e=1.1 \times 10^{6}$. (For interpretation of the references to color in this figure legend, the reader is referred to the Web version of this article.)

but they influence the flow distribution over the wing modifying the wing load. The effect of these cells will be addressed further.

The root and tip vortices are also visible in Fig. 8, A and B respectively. The tip vortex is composed by the main vortex rotating in the pressure-to-suction surface wing direction which is then enveloped by the structures emitted by the flap. The flap element structures are originated by the flow leakage from pressure to suction surfaces and they are counter-rotating with respect to the main tip vortex. The interaction between the main and the flap structures can be observed in both G-LES and G-URANS approaches. The flow on the root vortex is more complex because of the interaction with the trampoline and the vortices originated from the hulls. In this case, the G-URANS cannot correctly reproduce the interaction between the hull and the wing flow. On each hull, three vortices can be distinguished.

One positive helicity vortex is generated from the bottom rounded surface of the hull ( $F_{1}$ and $F_{2}$ in Fig. 9 ) and two positive helicity vortices are emitted from the edges on the upper surface of the hull $\left(D_{1}, D_{2}\right.$, and
$E_{1}, E_{2}$ ). These vortices are aligned with the hull, up to the moment they impact the trampoline spar or they interact with lower vortices. In this case, they deviate aligning with the wind direction. Furthermore, the two upper vortices on the leeward hull $\left(E_{1}\right.$ and $\left.E_{2}\right)$ finally interact with the flow structures of the wing root vortex. These two vortices are counter rotating.

Table 3

Time-averaged $C_{L}$ and $C_{D}$ values, calculated with respect to the steady wind axes $\mathrm{x}_{\mathrm{w}}$ and $\mathrm{y}_{\mathrm{w}}$ above $\mathrm{h}_{\mathrm{ref}}$, (Fig. 4), for the different simulations.

\begin{tabular}{llll}
\hline & WG-URANS & G-URANS & G-LES \\
\hline$C_{L}$ & 1.204 & 1.563 & 1.627 \\
$C_{\text {Lmain }}$ & 0.846 & 0.980 & 1.011 \\
$C_{\text {Lffap }}$ & 0.358 & 0.583 & 0.616 \\
$C_{D}$ & 0.389 & 0.528 & 0.464 \\
$C_{\text {Dmain }}$ & 0.047 & 0.058 & 0.052 \\
$C_{D \text { ffap }}$ & 0.342 & 0.470 & 0.412 \\
\hline
\end{tabular}
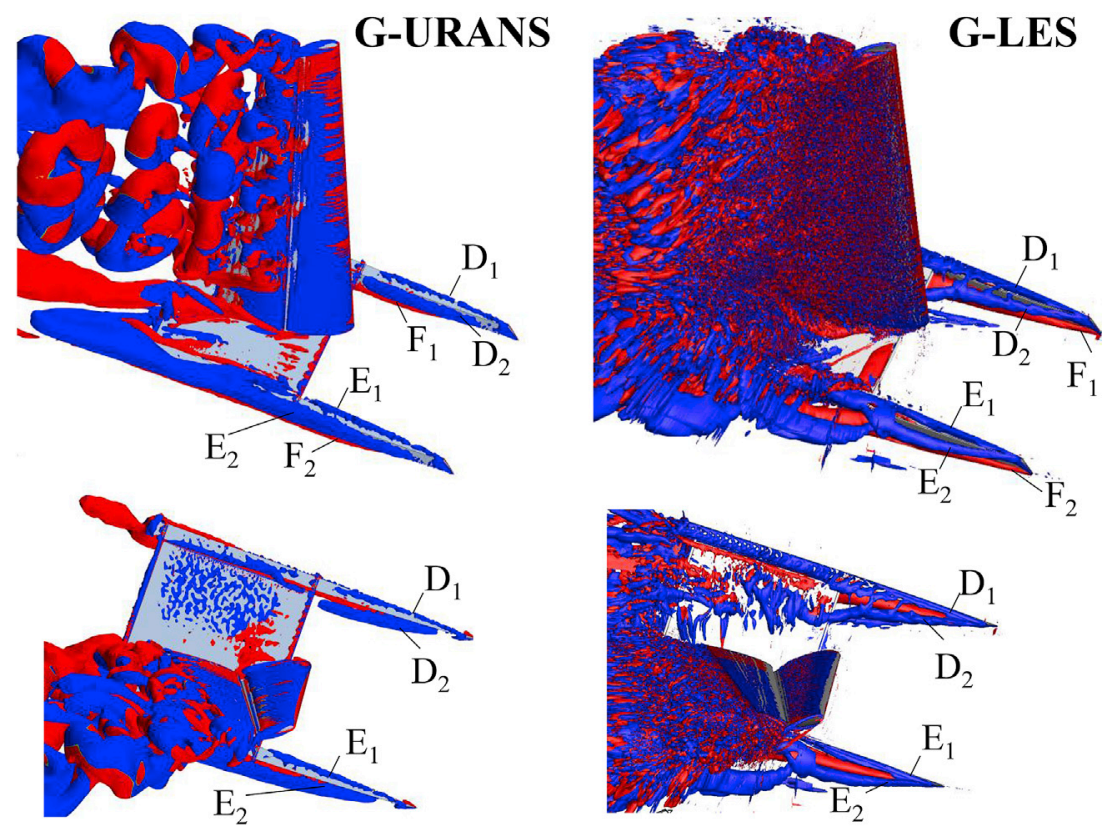

Fig. 9. Iso-surface on $Q$-criterion on the G-URANS simulation $\left(Q=1 / \mathrm{s}^{2}\right)$ and the G-LES simulation $\left(Q=10^{4} / \mathrm{s}^{2}\right), \operatorname{Re}=1.1 \times 10^{6}$. 


\subsection{Force coefficients comparison}

The aerodynamic coefficients, $C_{L}$ and $C_{D}$, and the pressure coefficient distribution $(C p)$ over the main element were extracted from the WGURANS, G-URANS and G-LES simulations and compared. In Table 3 the $C_{L}$ and $C_{D}$ are reported for the three numerical simulations. The coefficients are time averaged over a wind period.

The unsteady wind simulations G-URANS and G-LES have increased lift coefficients by $29.8 \%$ and $35.1 \%$ with respect to the WG-URANS simulation. The G-URANS and the G-LES simulations are in good agreement with a gap of $4.1 \%$ in $\mathrm{C}_{\mathrm{L}}$ and $13.7 \%$ in $\mathrm{C}_{\mathrm{D}}$. To go further, the GLES predicts a larger global $\mathrm{C}_{\mathrm{L}}$ compared to the G-URANS which is largely due to a more elevated flap lift. Indeed, as it will be shown in the next section, the flow separation on the flap is less significant in the LES case leading then to larger lift capabilities and lower drag.

The $C p$ profiles (Fig. 10) highlight also the good agreement between the G-URANS the G-LES simulations on the three wing sections. GURANS $C p$ profiles look like an offset of the WG-URANS pressure distributions. The suction capabilities of the main element are indeed increased by $23 \%$. The same effect can be inferred by the G-LES pressure profiles. The increase in suction is caused by the effect of the unsteady wind on the wing. This unsteadiness leads to a modification of the flow conditions especially in the slot region modifying the circulation around the main and hence its lift capabilities (the circulation effect described by Smith (1975). The improvement of the lift with the unsteady wind will be dealt more in detail in section 4 . On the $\mathrm{z}^{*}=0.25$ section, the local airfoil generates lift even if the local $\alpha$ is slightly negative, as it can be inferred from the $C p$ profile. Indeed, due to the camber of the global airfoil composed by the main element and the flap (deflected by $35^{\circ}$ ), the zero-lift angle of attack for such an airfoil is negative making possible the generation of lift even for a certain range of negative $\alpha$.

The two numerical analyses with unsteady wind modeling show good agreement on the three reference sections except for the L.E. zone. Here the suction has been differently estimated since the transition, which is taken into account by G-LES, is not predicted by G-URANS. The G-LES simulation highlights the presence of a laminar separation bubble giving origin to a second pressure peak. The length of the bubble increases moving upwards on the wingspan ranging between $18 \%$ and $20 \%$ of the main chord at $z^{*}=0.25$ and $z^{*}=0.50$ and between $15 \%$ and $25 \%$ at $z^{*}=0.75$. One of the limits of the URANS with respect to the LES is precisely the difficulty to predict the laminar/turbulent transition over the wing surface, including the laminar separation bubble (LSB). The URANS model is indeed fully turbulent while LES compute laminar to turbulent transition and laminar separation bubble (however, an accurate prediction of the wall friction, especially with a wall model, remains challenging). Despite this flaw, URANS predicts averaged lift and drag coefficients as well as pressure distributions ( $\mathrm{Cp}$ ) that are in good agreement with LES. Moreover, the main flow patterns are similar with both methods. Thus, URANS can be used to carry out a performance analysis of the wingsail at reasonable computational cost (compared to LES) as well as to perform parametric studies with a good accuracy/cost ratio.

The lift signal with time has been carried out in both the G-URANS ad G-LES simulations for comparison (Fig. 11). The lift signal presents a sinusoidal shape of the same frequency as the unsteady wind for both the numerical simulations. The comparison of the two curves represented in Fig. 11 shows good agreement between the two numerical approaches.

\subsection{Flowfield comparison between the g-les and g-urans simulations}

In the full-scale analysis, the flowfield issued from the G-URANS simulation has been compared to the G-LES one. The comparison analyzed both velocity and turbulent kinetic energy characteristics on the flowfield region upon the flap surface. In this zone, indeed, the flow prediction is complicated by the interaction of the different layers composing the confluent boundary layer and by the possibility of a
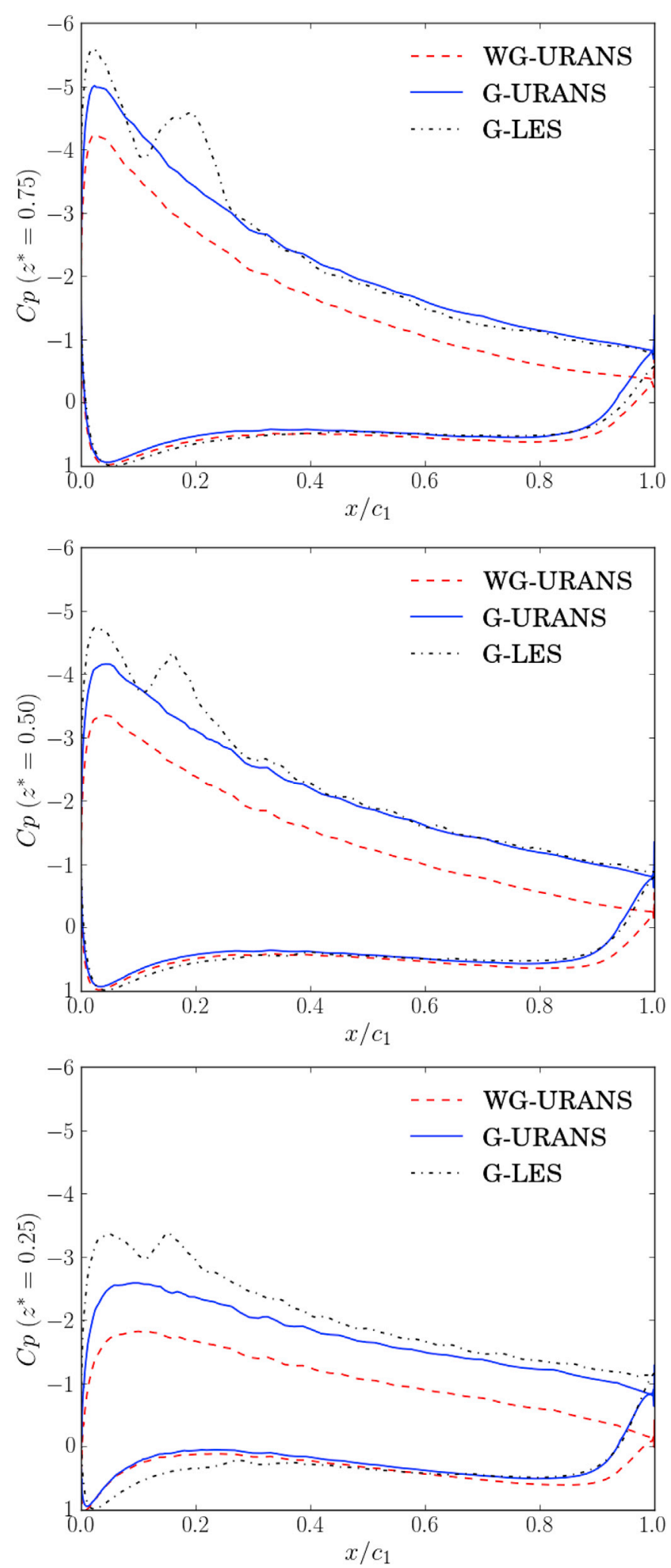

Fig. 10. $C p$ comparison on three sections of the main element of the wingsail $\left(z^{*}=0.25, z^{*}=0.50\right.$ and $\left.z^{*}=0.75\right)$ among the URANS and the LES simulations.

massive flow separation which is more difficult to model by the URANS approach.

\subsubsection{Velocity field}

The scalar maps of the dimensionless averaged velocity magnitude 


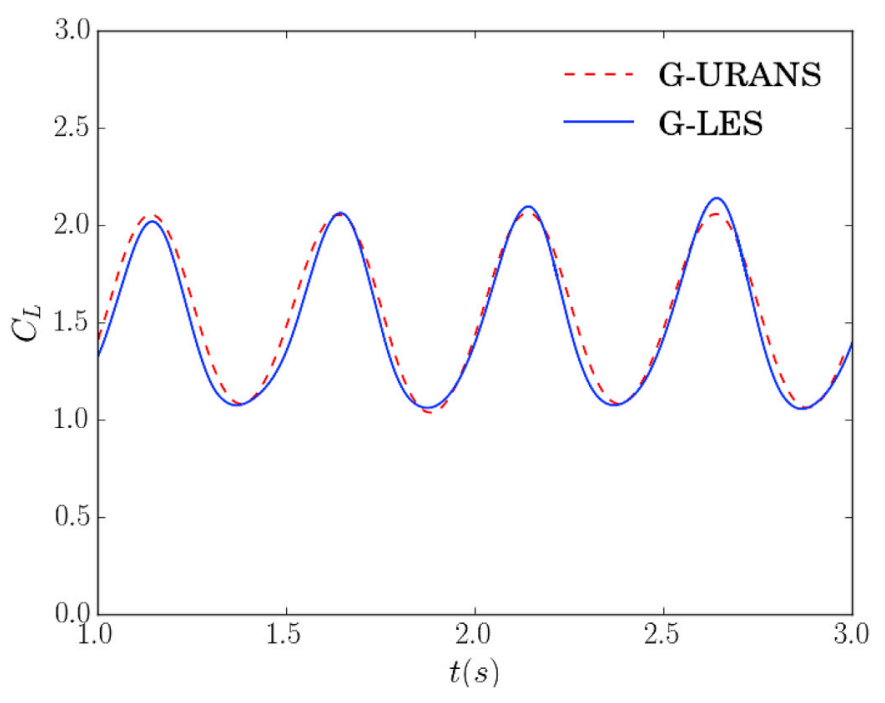

Fig. 11. Comparison of the $C_{L}(t)$ for the G-URANS and G-LES simulations.
$V / V_{\infty}$ on the flap surface of G-URANS and G-LES are reported in Fig. 12. The flow separates from the flap surface near its L.E. on the three sections considered. However, due to the influence of the wind pulsation, a high vorticity zone takes place downstream of the flap L.E. creating a recirculation bubble in contact with the flap wall. As described by (Greenblatt and Wygnanski, 2000), downstream of the bubble, a region of opposing vorticity takes place on the flap surface making possible a local flow reattachment. This phenomenon is captured by both the G-LES and G-URANS simulations. However, the G-LES simulation shows the contouring of the flow around the flap L.E. which is not reproduced by the URANS. This contouring leads to an increase of the flap lift (Table 3) for the LES reducing also the drag amount since the separated region on the flap is less extended. Furthermore, on the flap suction side, G-LES predicts a separation (corresponding to a low-velocity region), especially close to the tip, which is progressively reduced when approaching the root. With URANS this separation is rather uniform along the span. The result is that the lift ensured by the flap is, on average along the span, increased in the LES calculation (compared to URANS). Low-velocity regions are well related to separation.

On the $z^{*}=0.25$ section, in the G-LES simulation, the recirculation

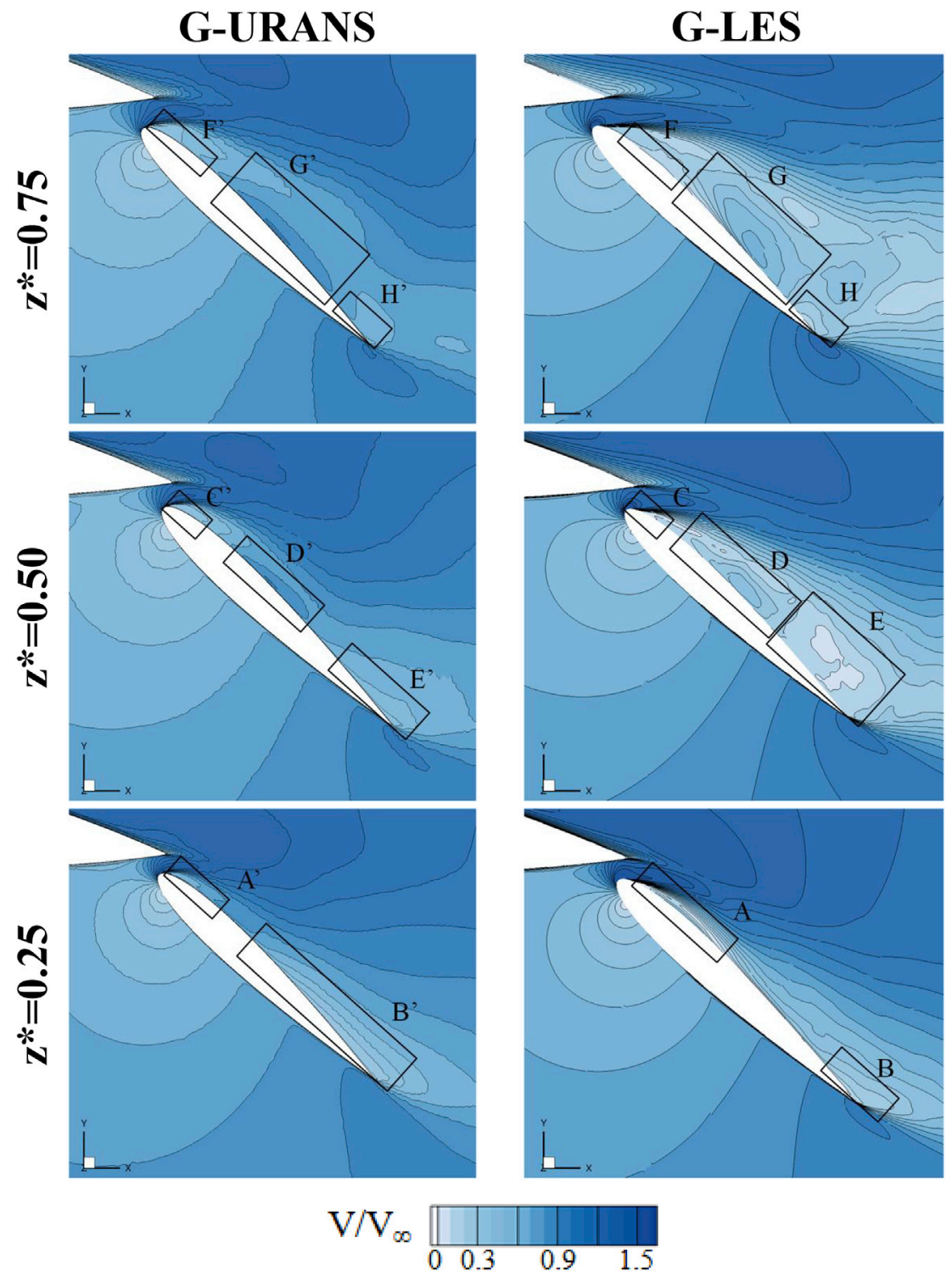

Fig. 12. Comparison of the velocity field on the flap region for the G-URANS and G-LES simulations for $z^{*}=0.25, z^{*}=0.50$ and $z^{*}=0.75$. 
bubble takes place at $5 \%$ of the flap chord and extends up to $30 \% c_{2}$ (A in Fig. 12). The flow then reattaches and separates again close to the T.E. (B). On G-URANS, the higher upwards deviation of the slot jet with respect to the LES case leads to the onset of the bubble closer to the flap L.E. The length of the bubble is also smaller, i.e. $20 \% c_{2}\left(\mathrm{~A}^{\prime}\right)$. The flow locally reattaches up to $40 \%$ of the flap chord where a new separation occurs extending up to the T.E. (B').

On the $z^{*}=0.50$ and $z^{*}=0.75$ sections, the flowfield of the G-LES and G-URANS simulations are in better agreement than in the previous case. Compared to the $z^{*}=0.25$ section, the jet trajectory appears more deviated due to the wider slot dimensions on the high wingsail sections. This different deviation of the jet leads to a thicker region of massively separated flow over the flap surface. The recirculation bubble $\left(\mathrm{C}, \mathrm{C}^{\prime}, \mathrm{F}, \mathrm{F}^{\prime}\right)$ takes place underneath the high vorticity zone originated by the shear stress of the jet. An opposite vorticity zone appears downstream of the flap surface leading to a local flow reattachment (D, $D^{\prime}, G, G^{\prime}$ ). The flow separates again near the flap T.E. (E, $\left.E^{\prime}, H, H^{\prime}\right)$. The lengths of the attached and separated zones are in good agreement between G-LES and G-URANS simulations on both the wingsail sections. However, the thickness of the separated region is more elevated on the G-LES simulation.

\subsubsection{Turbulent kinetic energy}

The scalar maps of the turbulent kinetic energy, on the three wingspan sections, are represented, for both the G-LES and G-URANS simulations, in Fig. 13.

The agreement between G-LES and G-URANS is, in this case, lower with respect to the velocity scalar maps. The G-LES predicts the turbulent kinetic energy in the flap L.E. region, where the shear stresses between the jet and the wall layers are elevated (A, B, C). On the $z^{*}=0.25$ section, this high $k$ zone lies on the flap surface (A). On the contrary, on the higher wingspan sections, the most intense turbulent zone is far from the flap surface and spreads moving downstream (B, C, D). The turbulent kinetic energy is convected inside the separated zone and it is more elevated in correspondence to the reattached zone over the flap surface. On the GURANS solution, instead, $k$ is concentrated on the regions over the flap surface where the flow reattaches locally $\left(\mathrm{A}^{\prime}, \mathrm{B}^{\prime}, \mathrm{D}^{\prime}\right)$. Close to the flap L.E., the turbulent kinetic energy is sensibly underestimated especially on the $z^{*}=0.50$ and $z^{*}=0.75$ sections $\left(C^{\prime}, E^{\prime}\right)$ and the effect of the shear layers is not reproduced.

\section{Wingsail response to unsteady wind}

The comparison between G-URANS and G-LES showed that the two

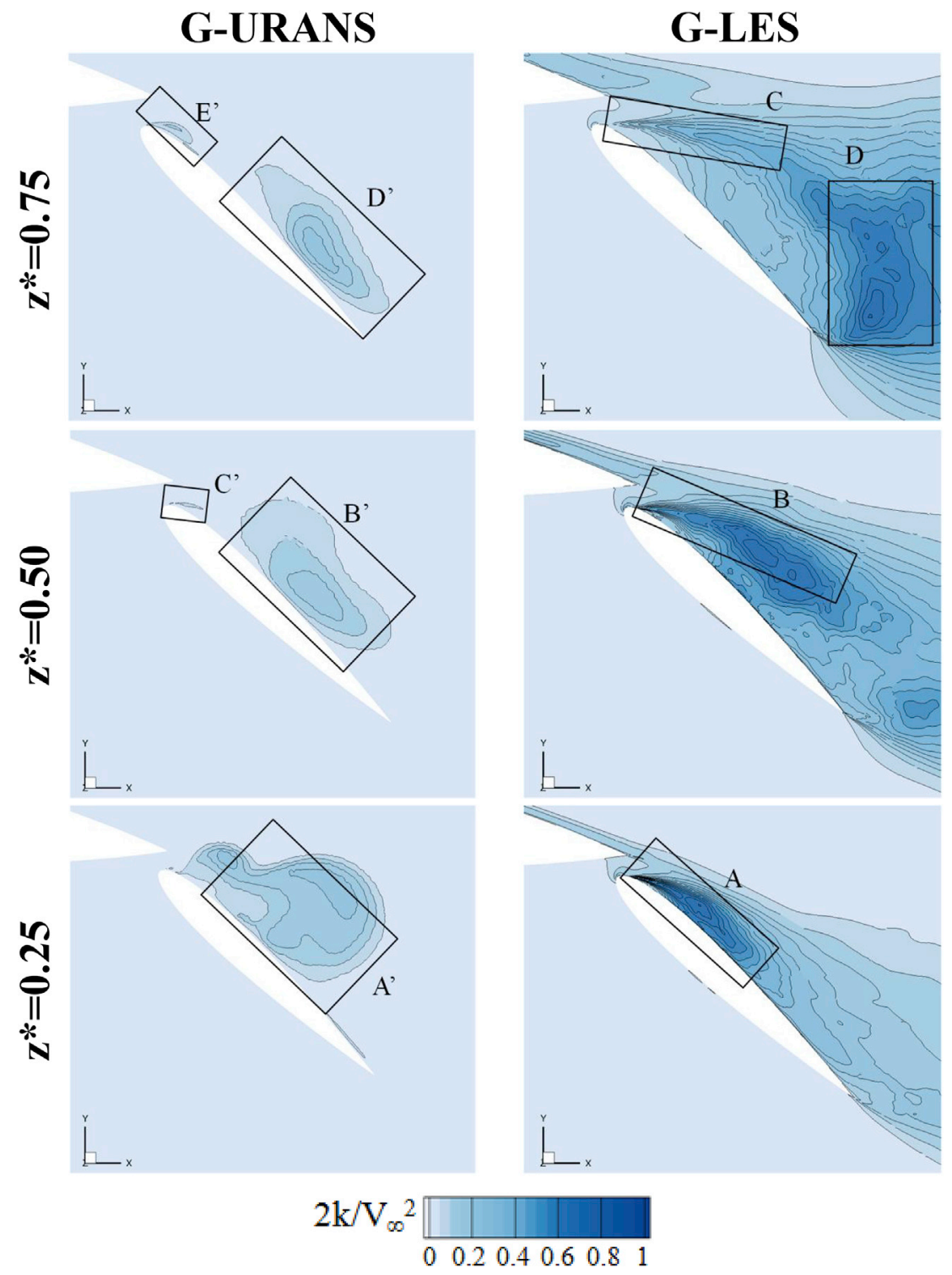

Fig. 13. Comparison of the turbulent kinetic energy $k$ field on the flap region for the G-URANS and G-LES simulations for $z^{*}=0.25, z^{*}=0.50$ and $z^{*}=0.75$. 
modeling approaches are in reasonable agreement with the URANS approach that predicts well the global coefficients of the wingsail and the macroscopic features of the flowfield. Due to these good characteristics and to a lower computational cost with respect to the LES, the URANS has been exploited to perform a parametric analysis of the unsteady wind. As observed in the aerodynamic coefficients analysis, one effect of the wind pulsation is to increase the mean lift of the wingsail. However, this enhancement could depend on the wind characteristics and on its frequency. Thus, to deepen the understanding of the pulsation influence on the wingsail performance, analyses were performed by modifying the frequency of the wind signal. URANS analyses were then performed imposing the wind frequency at $F^{+}=0.156, F^{+}=0.312, F^{+}=1.246$ and $F^{+}=2.492$.

\subsection{Unsteady wind effect on the jet of the slot}

The sinusoidal variation of the wind is responsible for the periodic movement of the flow on the wingsail. This periodic movement leads to a jet pulsation in the wing slot region which acts similarly to flow separation control devices adopted in some high-lift configurations. (Nishri and Wygnanski, 1998) studied a configuration similar to the wingsail, with a pulsed jet acting in a slotted flap geometry (Fig. 14) to analyze the effect of a pulsed jet on the flow separation and reattachment over the flap. Deeply, they modified the momentum and the pulsation frequency of the jet to detect the conditions at which a flow reattachment can take place over the flap surface at different slot $y_{F}$ settings.

To express the jet momentum, $C_{\mu}=2 V_{j}^{2} y_{F} /\left(V_{\infty}^{2} c_{2}\right)$ was introduced, where $V_{j}$ is the averaged velocity in the slot, $y_{F}$ the transverse distance of the slot and $c_{2}$ the flap chord. The jet pulsation allowed the flow reattachment if the jet pulsation frequency was within a certain range of frequencies, providing a momentum higher than a certain threshold value (Nishri and Wygnanski, 1998). They reported the minimum $C_{\mu}$ needed at different frequencies to provide the flow reattachment. The $C_{\mu}-F^{+}$threshold curves for reattachment at $y_{F} / c_{2}=0.6 \%$ and $y_{F} / c_{2}=1.0 \%$ carried out by (Nishri and Wygnanski, 1998) are represented in Fig. 15. The curves represent the minimum $C_{\mu}$ required at each frequency to reattach the flow over a flap $8^{\circ}$ more deflected than the deflection angle at which separation occurs. The zone above the threshold curve represents the jet conditions for which the flow reattachment is possible. Both the frequency range and the minimum momentum coefficient allowing the flow reattachment are dependent on the Reynolds number and length scale ratio $y_{F} / c_{2}$ (Nishri and Wygnanski, 1998). The range of frequencies at which the flow reattachment is effective reduces with the increase of the slot size while the minimum $C_{\mu}$, at a given frequency, increases.

In order to understand the actual capabilities of flow reattachment over the wingsail, the averaged $C_{\mu}$ of the jet of the slot was estimated at the difference wind frequencies, on two sections located at $z^{*}=0.346$ and $z^{*}=0.692$ (here the $y_{F} / c_{2}$ is respectively $6.47 \%$ and $7.11 \%$ ). The respective points have been plotted on the $C_{\mu}-F^{+}$scheme in Fig. 15. It can be highlighted that the range of frequencies studied by (Nishri and Wygnanski, 1998) are the same as the wind unsteady model on the wingsail. The $\mathrm{C}_{\mu}$ values for the wingsail lie above the threshold curves of

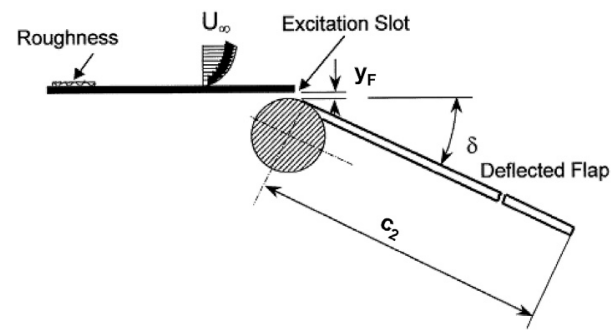

Fig. 14. Scheme of the flap device studied by (Nishri and Wygnanski, 1998).

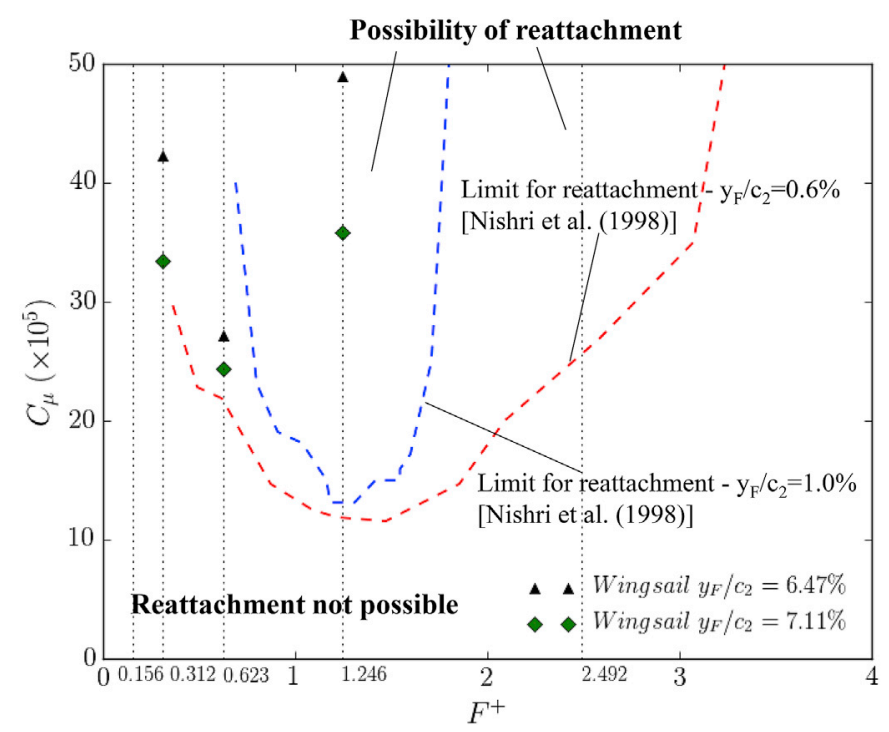

Fig. 15. Averaged $C_{\mu}$ points for the wingsail at different frequencies on two spanwise locations on the threshold reattached curves carried out by (Nishri and Wygnanski, 1998).

(Nishri and Wygnanski, 1998) indicating a possibility of flow reattachment over the flap. Nevertheless, on the wingsail, the reattachment conditions are more severe than the ones analyzed by (Nishri and Wygnanski, 1998) requiring then a more elevated momentum at a fixed pulsation frequency. There are two different reasons. Firstly, on the wingsail, the slot is wider with the $y_{F} / c_{2}$ varying between $6 \%$ and $7 \%$, instead of the $0.6 \%$ and $1.0 \%$ analyzed in the reference study. At the same time, as described by (Fiumara, 2017), on the mid-high flap sections of the wingsail the flow separates already at $\delta=25^{\circ}$. The difference between the separation and the reattaching angle considered here (i.e. $35^{\circ}$ ) is $10^{\circ}$ instead of the $8^{\circ}$ considered by (Nishri and Wygnanski, 1998). Hence, the threshold reattachment curve for the wingsail should be shifted upwards (i.e. for larger $C_{\mu}$ ) ranging in a frequency interval smaller than the one of the wider slot curve reported in Fig. 15.

The $C_{\mu}$ required achieving a stable flow reattachment must be larger than the one calculated on the wingsail. This is true for all the frequencies except the one included in the range $1.2<F^{+}<1.5$. Within this range, the minimum $C_{\mu}$ condition is independent of both the Reynolds number and the slot size (Nishri and Wygnanski, 1998) and hence the probability of flow reattachment is more elevated. The frequency $F^{+}=1.246$ is exactly inside this frequency range. All the other frequencies examined, except the $F^{+}=0.156$, can lead to a flow reattachment depending on the amount of the momentum blown by the jet.

In the reattachment process, a high vorticity zone takes place in the flap L.E. zone (Greenblatt and Wygnanski, 2000) (Fig. 16) forming a flow structure similar to LEV. Here, the flow encloses a dead air region forming the recirculation bubble described in the previous sections. The flow reattachment occurs downstream of this bubble. The reattachment condition is maintained if the air blown by the jet prevents the bubble burst leading to flow separation. Indeed, the length of this bubble reduces with the increase of $C_{\mu}$ or $F^{+}$(Nishri and Wygnanski, 1998), (Fiumara, 2017). This phenomenon can be observed also on the flap L.E. of the wingsail modifying the frequency of the unsteady wind as shown in Fig. 16. Thus, at low frequencies, the bubble length is elevated with a higher probability of a bubble burst. The flow can then separate again nullifying the reattachment effect of the jet pulsation. Thus, generally, the flow reattachment capabilities increase with the jet frequency. However, there is an upper limit of frequency at which the flow reattachment cannot take place. When the pulsation frequencies are too elevated the flow fluctuations are more rapidly dissipated downstream of the flap surface (Greenblatt and Wygnanski, 2000) with the flow 

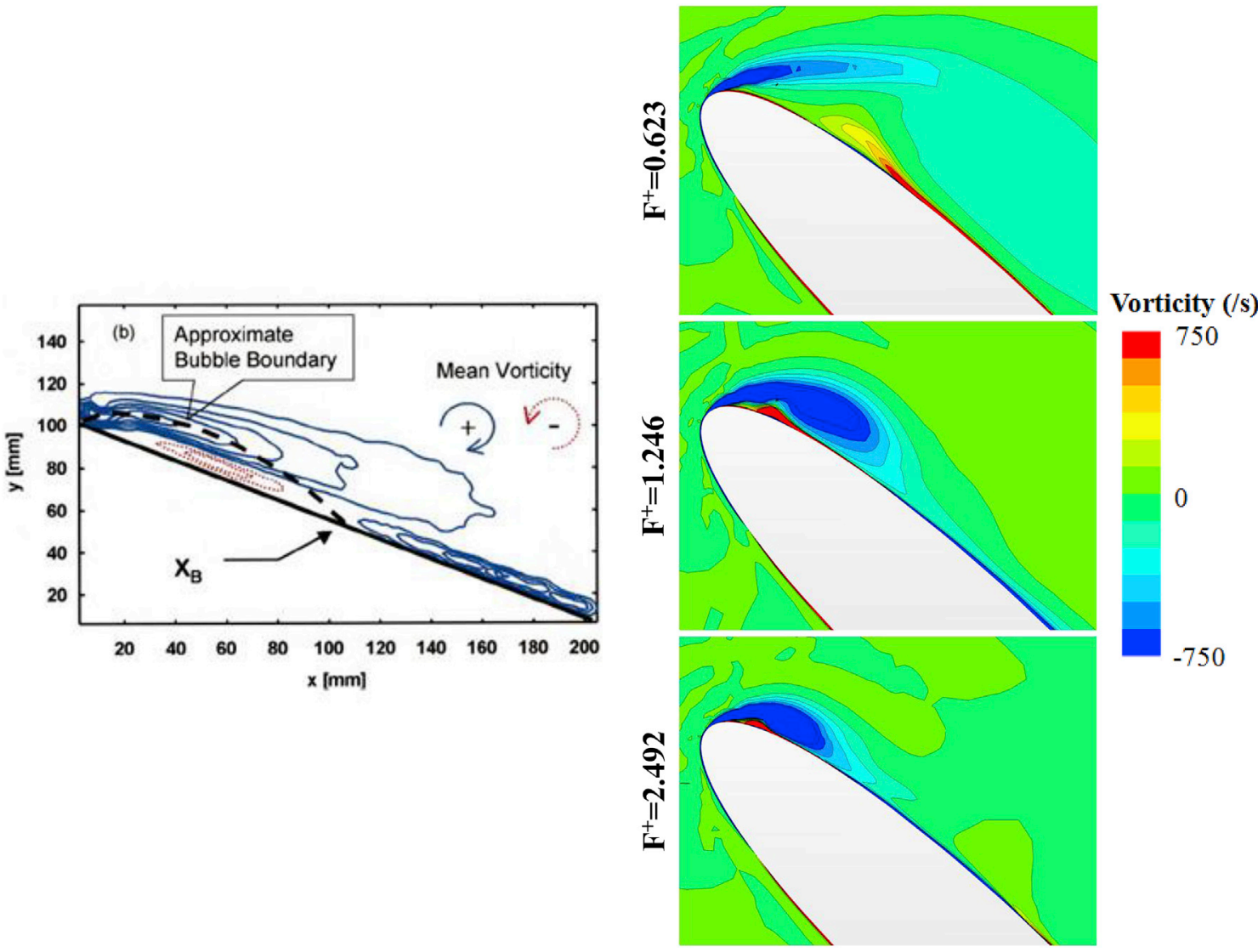

Fig. 16. Vorticity isolines over a slotted flap in case of flow reattachment by jet pulsation from (Greenblatt and Wygnanski, 2000) (left) and vorticity color maps on the flap L.E. of the wingsail at different wind frequencies. (For interpretation of the references to color in this figure legend, the reader is referred to the Web version of this article.)

separation that occurs from the flap T.E. region where the boundary layer is thicker.

\subsection{Flow feature modification with wind frequency}

As discussed in section 4.1, the periodic oscillation due to the unsteady wind makes the flow reattachment possible on the flap L.E. This reattachment is not uniform along the wingspan causing the formation of the stall cells observed in 3.1. Stall cells usually take place on wings after the stall onset. They originate from a non-uniform spanwise flow separation starting from the wing T.E. The separation line delimiting the attached flow from the separated one is parallel to the wing L.E. However, this line is not straight along the span direction but it has instead a wavy shape. As described by (Manolesos and Voutsinas, 2014), a stall cell is made of a vortex system composed by two counter-rotating vortices evolving in the chordwise direction (Fig. 17), named SC vortices, and two spanwise vortices, i.e. the separation line (SL) and the T.E. vortices.

The origin of these cells is usually due to the occurrence of the flow separation. On the wingsail, instead, these structures are originated from a flow re-attachment on the flap surface due to the jet pulsation created by the unsteady wind. The vortex system composing these cells makes possible the further flow reattachment downstream of the flap surface.

These structures have a periodic evolution spanwise. The evolution of the flow on the wing around $z^{*}=34.6 \%$ for $F^{+}=0.623$ is shown in Fig. 18. The cells are completely formed on the flap surface when the maximum peak lift condition is achieved since the flow reattachment effect of the vortices composing the cells is more effective. The extent of the attached zone on the flap surface is then larger. The cells are then convected downstream with the vortex structures that, leaving the flap T.E., reduce the flow reattachment effect. At the same time, close to the
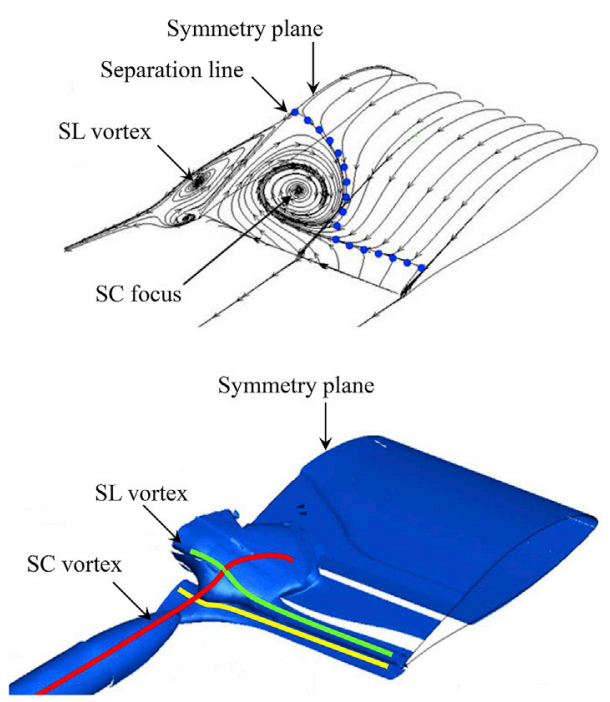

Fig. 17. Stall cell structures from (Manolesos and Voutsinas, 2014).

flap L.E., the length of the recirculation bubble increases, enlarging toward the flap T.E. At this moment, the minimum peak lift is achieved. At the same time, new stall cells start to arise on the flap L.E., adjacent to the zone where the previous cells developed.

In Fig. 19 the evolution of the flow pattern on the flap surface is reported at different $F^{+}$. At low wind frequency $\left(F^{+}=0.156\right)$, the flow is still separated on the flap surface. The pulsation is too low to allow flow reattachment (Fig. 15). A local reattachment can be observed on the low 


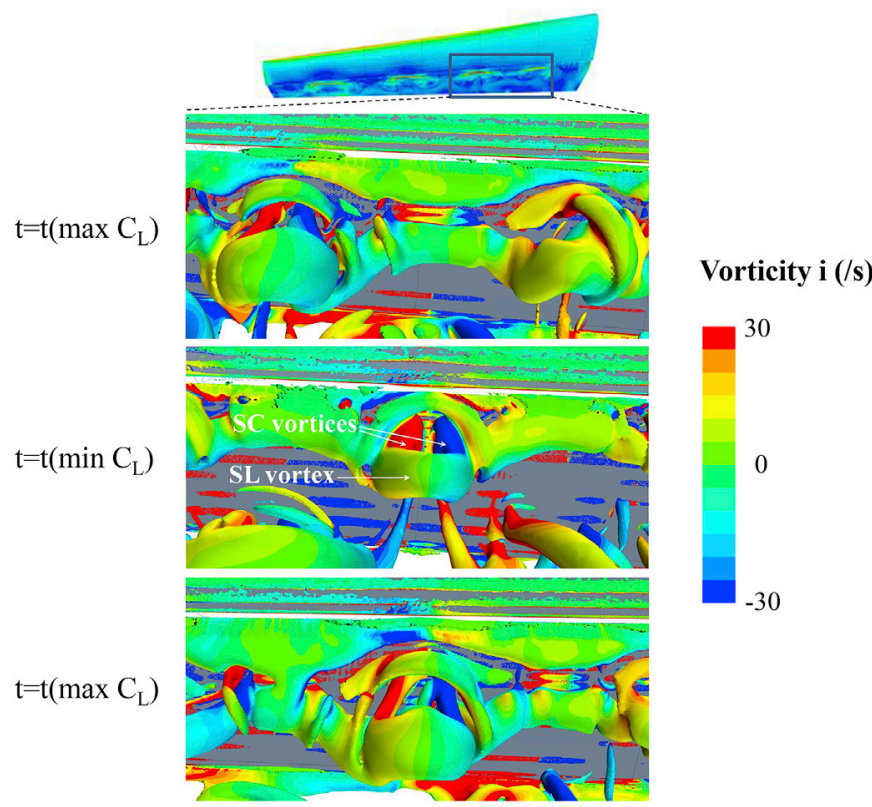

Fig. 18. Flow evolution over the flap surface in the span region included between $z^{*}=30 \%$ and $z^{*}=39 \%$ for $F^{+}=0.632$. Isosurfaces on Q-criterion with vorticity scalar maps.
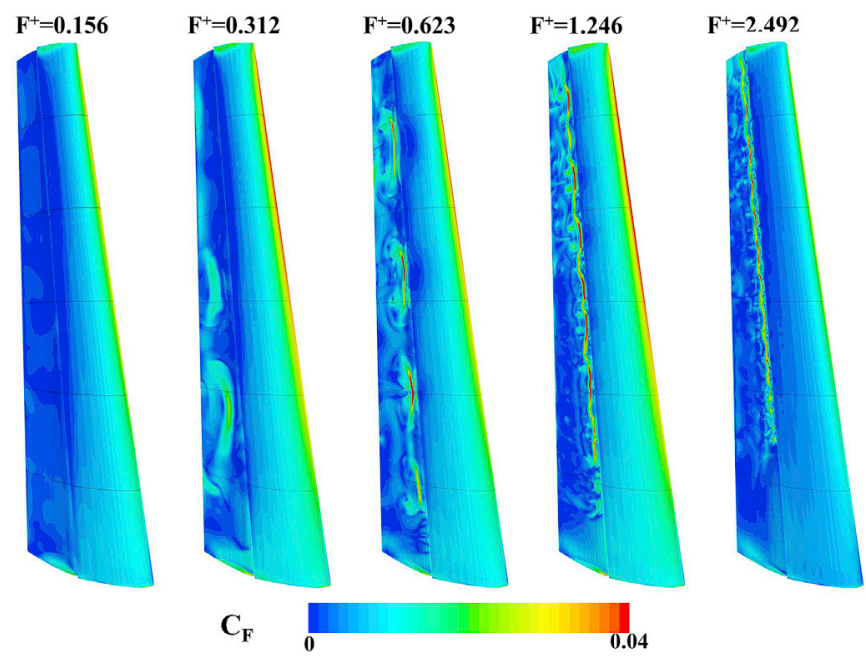

Fig. 19. Skin friction colormaps on the wingsail upper surface at different frequencies of the unsteady wind in the maximum peak lift condition.

flap sections when the wind frequency achieves $F^{+}=0.312$. Here, two flow structures take place at $z^{*}=0.39$ and $z^{*}=0.56$. At $F^{+}=0.623$ the flow is organized in cells regularly distributed on the wingspan. Four stall cells arise on the flap surface. The increase of $F^{+}$reduces the span size of the stall cells while the number of cells appearing in the flap increases. In particular, between $F^{+}=0.623$ and $F^{+}=1.246$, the number of stall cells doubles from 4 to 8 (Table 4).

At $F^{+}=2.492$ the cell number increases to 12 . The extent of the region where the cells develop reduces when increasing the frequency. The lower cell at $F^{+}=0.623$ is located at $z^{*}=13 \%$ moving at $21.6 \%$ at $F^{+}=1.246$ and $26 \%$ at $F^{+}=2.492$.

Table 4

Number of stall cells for each wind frequency.

\begin{tabular}{llllll}
\hline$F^{+}$ & 0.156 & 0.312 & 0.623 & 1.246 & 2.492 \\
\hline N cells & 0 & 2 & 4 & 8 & 12 \\
\hline
\end{tabular}

\subsection{Separated zones with the wind frequency}

The presence of the stall cells modifies the flow features over the flap surface leading to a modification of the wingsail performance. In Fig. 20 and Fig. 21, the attached, separated and the recirculation flow zones have been represented for the maximum and the minimum peak lift conditions respectively.

When the maximum peak lift condition is achieved, the SC vortices and the SL vortex flowing on the flap surface allow local flow reattachment improving the flap lift capabilities (Fig. 20). Due to the shortening of the recirculation bubble close to the flap L.E., the attached zone moves towards the L.E., in the region where the flap pressure peak takes place and the pressure suction is more elevated. Because of the increase in the number of stall cells with the wind frequency, the attached zone becomes more regular in the span direction thus leading to a larger suction that contains the entire flap span. Furthermore, the extent of the attached zone at the root of the flap also tends to increase with $\mathrm{F}^{+}$. Because of these two mechanisms, the flap effectiveness tends then to increase with wind frequency as it can be observed from Table 5 .

The main element lift consequently increases with the wind frequency due to the augmentation of the crossfield component of the jet velocity at T.E. $\left(v_{j}\right)$. This velocity increase affects the circulation of the main element (Smith, 1975), then improving its lift performance. Thus, the lift of both the main and the flap increases with $F^{+}$keeping, as shown in a previous section, a constant load distribution.

In the minimum peak lift condition, new stall cells start to form on the flap surface while the recirculation bubble has enlarged moving towards the flap T.E. (Fig. 21). The flow remains attached where the new cells originate. The extent of this zone is broader in the low-frequency condition due to the larger size of the cell in both spanwise and chordwise directions. Close to the flap L.E. the flow is dominated by the recirculation bubble that prevents the high suction due to the pressure peak contrary to the maximum lift condition. The flap effectiveness in generating lift is then lower than in the maximum lift condition case. At $F^{+}=0.623$ the attached regions corresponding to stall cells are larger than at $F^{+}=1.246$ due to the larger dimensions of the cells leading to a more elevated flap lift. At the highest frequency $F^{+}=2.492$, a massive flow separation arises from the flap T.E. extending close to the flap L.E. This massive separated region causes a significant decrease of the flap effectiveness with respect to the lower wind frequencies leading to a lateral force in the upper-to-lower airfoil wing surface direction. The decay in flap lift can be highlighted from Table 6.

In this condition, the main element lift slightly increases up to $F^{+}=1.246$ and then reduces. The variation of the main lift is whatever

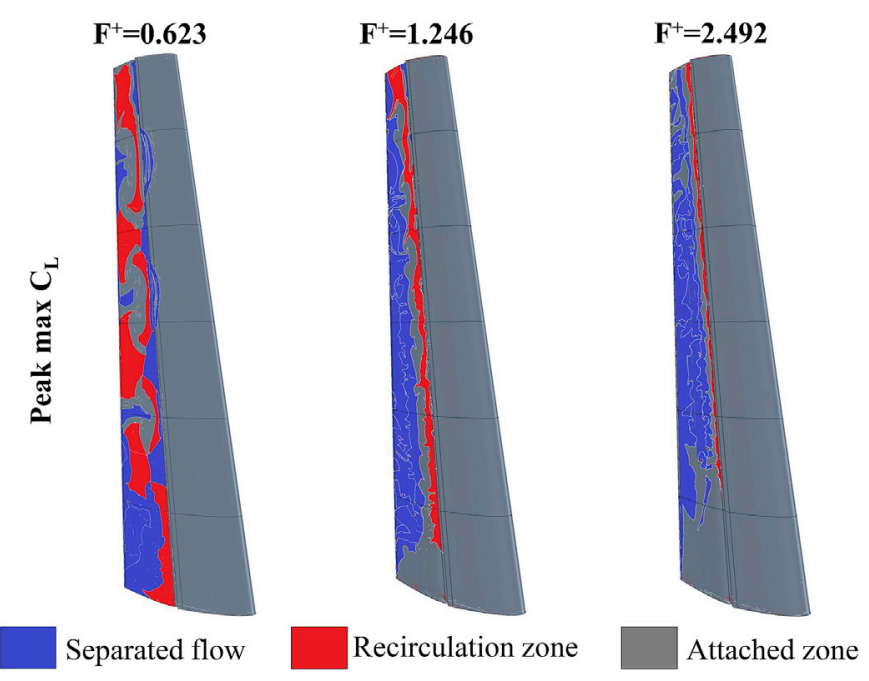

Fig. 20. Instantaneous flow pattern on the wing surface at the different wind frequencies in the maximum lift condition. 


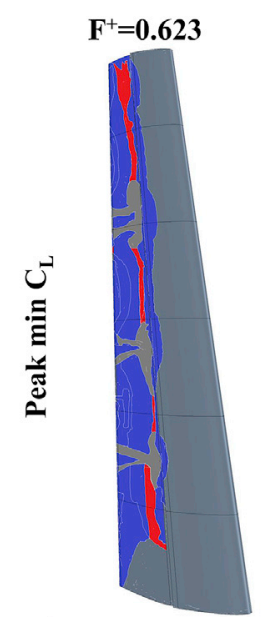

Separated flow

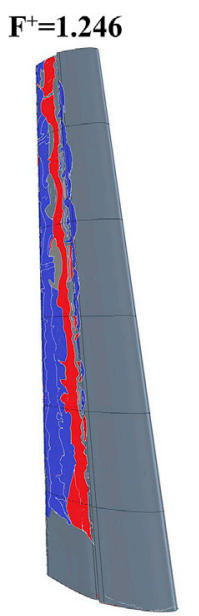

Recirculation zone

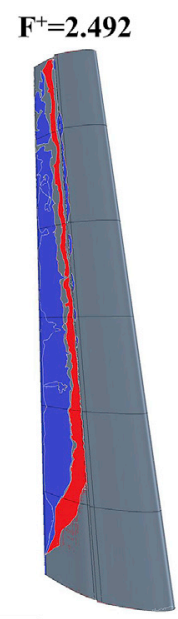

Attached zone
Fig. 21. Instantaneous flow pattern on the wing surface at the different wind frequencies in the minimum lift condition.

Table 5

Main and flap lift at different wind frequencies in the maximum peak lift condition together with the crossfield component of the jet at the main T.E.

\begin{tabular}{llll}
\hline$F^{+}$ & 0.623 & 1.246 & 2.492 \\
\hline$C_{\text {Lmain }}$ & 1.292 & 1.560 & 1.655 \\
$C_{L f l a p}$ & 0.900 & 1.077 & 1.353 \\
$v j / V_{\infty}$ & 0.45 & 0.51 & 0.82 \\
\hline
\end{tabular}

Table 6

Main and flap lift at different wind frequencies in the minimum peak lift condition together with the crossfield component of the jet at the main T.E.

\begin{tabular}{llll}
\hline$F^{+}$ & 0.623 & 1.246 & 2.492 \\
\hline$C_{\text {Lmain }}$ & 0.609 & 0.646 & 0.516 \\
$C_{L f l a p}$ & 0.265 & 0.059 & -0.128 \\
$v j / V_{\infty}$ & 0.50 & 0.90 & 0.62 \\
\hline
\end{tabular}

smaller than in the maximum lift peak condition. The increase in frequency lowers the flap lift.

\subsection{Lift modification with the unsteady wind}

The lift signals of the wingsail have been carried out for each wind frequency analyzed to better link the wingsail performance with the flow phenomena described in the previous sections. In Fig. 22 the averaged $C_{L}$, as well as its maximum and minimum peak values, are represented for the different wind frequencies.

The maximum averaged lift is achieved for $F^{+}=1.246$, i.e. the frequency after which, according to (Greenblatt and Wygnanski, 2000) the probability of a flow reattachment is more elevated. The maximum peak lift increases monotonically with the wind frequency while the minimum peak lift increases up to $F^{+}=0.312$ and then reduces. The amplitude of the $C_{L}$ signal amplifies then with the increase of the frequency. Furthermore, the reduction of the minimum lift becomes more elevated at $F^{+}=2.492$. In this case, the $C_{L}$ lowers by $65 \%$ with respect to $F^{+}=1.246$ while the difference in $C_{L}$, between $F^{+}=1.246$ and $F^{+}=0.623$, is only $10 \%$.

The load of the two elements is differently distributed as wind frequency varies. In Fig. 23 the ratio between the flap lift and the total lift of the wingsail has been reported, in both the maximum and minimum peak lift conditions, as a function of $F^{+}$.

In the maximum lift peak condition, the $C_{L}$ provided by the flap is

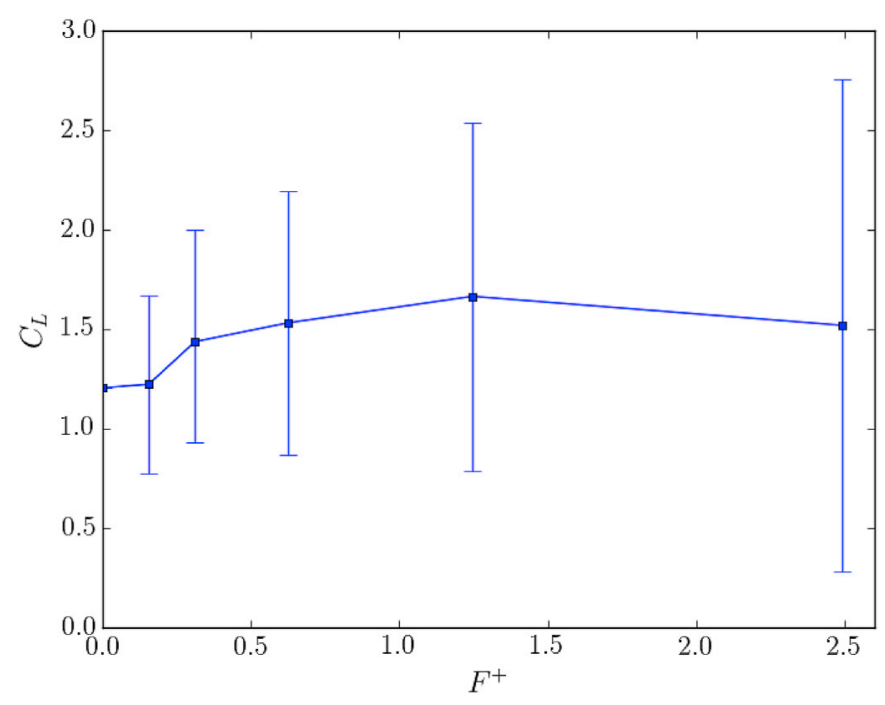

Fig. 22. Evolution with the wind frequency of the averaged $C_{L}$ and the maximum and minimum peaks in $C_{L}$.

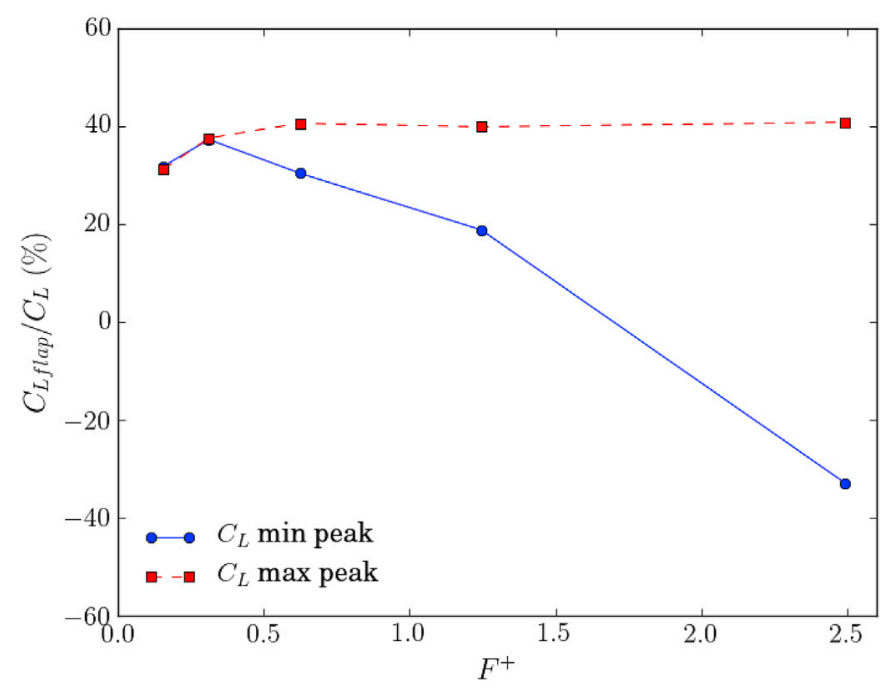

Fig. 23. Flap lift with respect to the whole wingsail lift at the different wind frequencies in the maximum and minimum peaks conditions.

about $40 \%$ of the total lift for dimensionless frequencies higher than 0.312 . This condition is almost constant for frequencies included between 0.623 and 2.492. In the minimum peak lift, the flap contribution decreases more and more with the $F^{+}$increase (Fig. 23) leading even negative lift values, hence a lateral force in the upper-to-lower airfoil wing surface direction, at $F^{+}=2.492$. This decrease is caused by a reduction of the flow attached area over the flap. At $F^{+}=0.156$ and $F^{+}=0.312$, the lift distribution of the two elements is constant in the maximum and minimum peak conditions.

To summarize, the wind frequency acts creating a pulse jet in the slot region leading to a local flow reattachment close to the flap L.E. This reattachment makes possible the onset of the stall cells whose vortex system further increases the extent of attached flow zone. The frequency of the unsteady wind affects the position of the attachment line on the flap chord and the size of the stall cells. The wind frequency increase makes the cells reduce in size, increasing their number, while the reattachment line moves towards the flap L.E. Thus the extent of the separated and attached regions over the flap surface depends directly on the frequency of the wind affecting the lift performance of the wingsail. The averaged lift tends to increase with the wind frequency but, at the same 
time, the amplitude of the lift signal with the time amplifies. In the maximum lift peak condition, both the main element and the flap generate more lift enhancing the wing performance when the frequency increases. Instead, in the minimum lift peak condition, the main element keeps a quite constant lift performance when the frequency is modified while on the flap the lift decreases with the wind increase.

\section{Conclusions}

Numerical analyses were carried out on a C-class catamaran in pulsing wind conditions as the first approach to unsteady wind modeling. A simplified wind model was set up considering a constant turbulence model in space and a sinusoidal variation of the wind speed. Both LES and URANS approaches were adopted for the simulations.

The URANS fails in detecting the turbulent features especially over the flap surface where the eddies are largely anisotropic. However, the URANS allows correct modeling of the global velocity characteristics around the wingsail when compared to the LES solution. Thus the lift and drag coefficients, as well as the pressure coefficients, are in very good agreement.

Both the numerical solutions show the formation of stall cells taking place over the flap surface. These cells originate from the local reattachment of the flow over the flap due to the pulsation of the jet of the slot generated by the flow fluctuation of the unsteady wind. The cells, composed of vortices, provoke a further reattachment of the flow over the flap surface affecting the wingsail performance.

The effect of the unsteady wind has further been analyzed exploiting the URANS approach. The lift performance of the wingsail is affected by the variation of the frequency of the unsteady wind with the lift increasing with the wind frequency. The averaged and amplitude variation of $\mathrm{C}_{\mathrm{L}}$ tends to increase with the wind frequency. The lift performance improvement is linked to the stall cells on the flap surface.

Due to the size reduction of the cells with the wind frequency and the augmentation of their number on the flap, the attached surface enlarges more and more increasing flap effectiveness.

\section{Acknowledgments}

This research has been partially funded by Assystem France (Toulouse, France). Special thanks to Laurent Neau for his support on this project. Numerical simulations, in particular, LES have been performed thanks to the computing means provided by GENCI (project 07178) and CALMIP (project p1425). These supports are greatly acknowledged.

\section{References}

America's Cup Class Rule, 2015 version 1.0, 31th March 2015.

Anderson, J.D., 2005. Fundamentals of Aerodynamics. Mc Graw Hill.

Beaupuits, J.P.P., Otárola, A., Rantakyrö, F.T., River, R.C., Radford, S.J.E., Nyman, L.-Å., 2004. Analysis of Wind Data Gathered at Chajnantor. ALMA Memo No, p. 467.

Bermejo-Moreno, I., Bodart, J., Larsson, J., Barney, B.M., Nichols, J.W., Jones, S., 2013. "Solving the Compressible Navier-stokes Equations on up to 1.97 Million Cores and 4.1 Trillion Points", SC'2013: Proceedings in the International Conference on High Performance Computing, Networking, Storage and Analysis.

Bethwaite, F., 1996. High Performance Sailing. Waterline Books, 1996.

Blakeley, A.W., Flay, R.G.J., Richards, P.J., 2012. Design and optimisation of multielement wing sails for multihull yachts. In: 18th Australasian Fluid Mechanics Conference, Launceston, Australia, pp. 3-7. December 2012.

Blakeley, A.W., Flay, R.G.J., Furukawa, H., Richards, P.J., 2015. Evaluation of multielement wingsail aerodynamics from Two-dimensional wind tunnel Investigations. In: 5th High Performance Yacht Design Conference, Auckland, pp. 10-12. March, 2015.

Bodart, J., Larsson, J., 2011. Wall-modeled Large Eddy Simulation in Complex Geometries with Application to High-lift Devices. Center for Turbulence Research. Annual Research Briefs 2011.
Bodart, J., Larsson, J., 2012. Sensor-based Computation of Transitional Flows Using Wallmodeled Large Eddy Simulation. Center for Turbulence Research. Annual Research Briefs 2012.

Bodart, J., Larsson, J., Moinz, P., 2013. Large eddy simulation of high-lift devices. In: $21^{\text {st }}$ AIAA Computational Fluid Dynamics Conference, pp. 24-27. June 2013, San Diego, CA.

Breitsamter, C., 2008. Unsteady flow phenomena associated with leading-edge vortices. Prog. Aero. Sci. 44 (1), 48-65. Jan. 2008.

Chapin, V., Gourdain, N., Verdin, N., Fiumara, A., Senter, J., 2015. Aerodynamic study of a two-element wingsail for high performance multihull yachts. In: 5th High Performance Yacht Design Conference, Auckland, pp. 10-12. March, 2015.

Charnock, H., 1955. Wind stress on a water surface. Quart J. Roy. Met Soc. 81, 639-640, 1955.

Cook, N.J., 1986. Designers Guide to Wind Loading of Building Structures, Part 1. BRE, Butterworths. January 1986.

Deck, S., Laraufie, R., 2013. Numerical Investigation of the flow Dynamics past a threeelement aerofoil. J. Fluid Mech. 732, 401-444, 2013.

Deck, S., 2005. Zonal-detached-Eddy simulation of the flow around a high-lift configuration. AIAA J. 43 (No. 11), 2372-2384. November 2005.

Ellington, C.P., van den Berg, C., Willmott, A.P., Thomas, A.L.R., 1996. Leading-edge vortices in insect flight. Nature 384, 626-630, 26 Dec. 1996.

Fiumara, A., Gourdain, N., Chapin, V., Senter, J., Bury, Y., 2016a. Numerical and experimental analysis of the flow around a two-element wingsail at Reynolds number $0.53 \times 10^{6}$. Int. J. Heat Fluid Flow 62, 538-551. December 2016.

Fiumara, A., Gourdain, N., Chapin, V., Senter, J., 2016b. Aerodynamic Analysis of 3D Multi-element Wings: an Application to Wingsails of Flying Boats. RAeS, Conference Paper, Bristol UK, pp. 19-21. July, 2016.

Fiumara, A., 2017. Study and Control of the Stall of a Multi-element Wingsail. Doctoral dissertation. ISAE-Supaéro, Toulouse (France).

Flay, R.G.J., Jackson, P.J., 1992. Flow simulations for wind tunnel studies of sail aerodynamics. J. Wind Eng. Ind. Aerod. 41-44, 2703-2714, 1992.

Gourdain, N., Bury, Y., Bodart, J., 2016. Large-Eddy Simulation and analysis of the controlled turbulent wake generated by a thick profile. In: RAeS 2016 Applied Aerodynamic Conference, vols. 19-21. July 2016, Bristol, UK.

Greenblatt, D., Wygnanski, I.J., 2000. The control of flow separation by periodic excitation. Prog. Aero. Sci. 36, 487-545, 2000.

Holmes, J.D., 2017. Roughness lengths and turbulence intensities for wind over water. In: 9th Asia-Pacific Conference on Wind Engineering, Auckland, New Zealand, pp. 3-7. December 2017.

Hui, M.C.H., Larsen, A., Xiang, H.F., 2009a. Wind turbulence characteristics study at the Stonecutters Bridge site: PartI - mean wind and turbulence intensities. J. Wind Eng. Ind. Aerod. 97 (2009), 22-36.

Hui, M.C.H., Larsen, A., Xiang, H.F., 2009b. Wind turbulence characteristics study at the Stonecutters Bridge site: PartII - wind power spectra, integral length scales and coherences. J. Wind Eng. Ind. Aerod. 97 (2009), 48-59.

Kawai, S., Larsson, J., 2012. Wall-modeling in large eddy simulation: length scales, grid resolution, and accuracy. Phys. Fluids 24. December 2011.

Magherini, M., Turnock, S.R., Campbell, I.M., 2014. Parameters affecting the performance of the C-Class wingsail. Trans. Rina: IJSCT 156 (1), 21-34, 2014.

Manolesos, M., Voutsinas, S.G., 2014. Study of a stall cell using stereo particle image velocimetry. Phys. Fluids 26 (045101), 2014.

Marchaj, C.W., 1980. Aero-hydro Dynamics of Sailing. Dodd, Mead, 1980.

Marchaj, C.A., 2003. Sail Performance - Technique for Maximizing Sail Power. McGrawHill, 2003.

Maxworthy, T., 1979. Experiments on the Weis-Fogh mechanism of lift generation by insects in hovering flight. Part 1. Dynamics of the 'fling'. J. Fluid Mech. 93 (Issue 1), 47-63, 12 July 1979.

Menter, F.R., 1994. Two-equation eddy-viscosity turbulence models for engineering applications. AIAA J. 32 (8), 1598-1605, 1994.

Muijres, F.T., Johansson, L.C., Barfield, R., Wolf, M., Spedding, G.R., Hedenström, A., 2008. Leading-edge vortex improves lift in slow-flying bats. Science 319, 29 Feb. 2008.

Nishri, B., Wygnanski, I.J., 1998. Effects of periodic excitation on turbulent separation from a flap. AIAA J. 36 (4), 1998.

Peña, A., Gryning, S.E., Mann, J., 2010. On the length-scale of the wind profile. Q. J. R. Meteorol. Soc. 136, 2119-2131. October 2010 Part B.

Shiau, B.S., Chen, Y.B., 2002. Observation in wind tunnel characteristics and velocity spectra near the ground at the coastal region. J. Wind Eng. Ind. Aerod. 90, 1671-1681, 2002.

Smith, A.M.O., 1975. High-lift aerodynamics. J. Aircraft 12 (6), 501-530.

Türk, M., Emeis, S., 2010. The dependence of offshore turbulence intensity on wind speed. J. Wind Eng. Ind. Aerod. 98 (2010), 466-471.

Viola, I., Arredondo-Galeana, A., 2017. The leading edge vortex of yacht sails. In: $4^{\text {th }}$ INNOV'SAIL International Conference. Jun 2017, Lorient, France.

Viola, I.M., Bartesaghi, S., Van-Renterghem, T., Ponzini, R., 2014. Detached eddy simulation of a sailing yacht. Ocean Eng. 90, 93-103, 2014.

Vreman, A.W., 2004. An eddy-viscosity subgrid-scale model for turbulent shear flow: algebraic theory and applications. Phys. Fluids 16, 3670-3681, 2004.

Yon, S., Katz, J., 1997. Study of the Unsteady Flow Features on a Stalled Wing. AIAA paper 97-1927. 